Article

\title{
Modeling of Carbon Dioxide Leakage from Storage Aquifers
}

\author{
Parvaneh Heidari and Hassan Hassanzadeh * (D) \\ Department of Chemical and Petroleum Engineering, Schulich School of Engineering, University of Calgary, \\ Calgary, AB T2N 1N4, Canada; heidari.p@gmail.com \\ * Correspondence: hhassanz@ucalgary.ca; Tel.: +1-403-210-6645
}

Received: 16 July 2018; Accepted: 18 October 2018; Published: 23 October 2018

\begin{abstract}
Long-term geological storage of $\mathrm{CO}_{2}$ in deep saline aquifers offers the possibility of sustaining access to fossil fuels while reducing emissions. However, prior to implementation, associated risks of $\mathrm{CO}_{2}$ leakage need to be carefully addressed to ensure safety of storage. $\mathrm{CO}_{2}$ storage takes place by several trapping mechanisms that are active on different time scales. The injected $\mathrm{CO}_{2}$ may be trapped under an impermeable rock due to structural trapping. Over time, the contribution of capillary, solubility, and mineral trapping mechanisms come into play. Leaky faults and fractures provide pathways for $\mathrm{CO}_{2}$ to migrate upward toward shallower depths and reduce the effectiveness of storage. Therefore, understanding the transport processes and the impact of various forces such as viscous, capillary and gravity is necessary. In this study, a mechanistic model is developed to investigate the influence of the driving forces on $\mathrm{CO}_{2}$ migration through a water saturated leakage pathway. The developed numerical model is used to determine leakage characteristics for different rock formations from a potential $\mathrm{CO}_{2}$ storage site in central Alberta, Canada. The model allows for preliminary analysis of $\mathrm{CO}_{2}$ leakage and finds applications in screening and site selection for geological storage of $\mathrm{CO}_{2}$ in deep saline aquifers.
\end{abstract}

Keywords: $\mathrm{CO}_{2}$ sequestration; leakage; fault; gravity number; capillary number

\section{Introduction}

It is generally accepted that increase in concentrations of greenhouse gases (GHG) such as carbon dioxide $\left(\mathrm{CO}_{2}\right)$, methane $\left(\mathrm{CH}_{4}\right)$ and nitrous oxide $\left(\mathrm{N}_{2} \mathrm{O}\right)$ is the main cause of global warming [1]. It has been reported that the anthropogenic emissions have increased atmospheric concentrations of $\mathrm{CO}_{2}$ by around 35\% during the last 200 years, from $280 \mathrm{ppm}$ in 1800 to $380 \mathrm{ppm}$ in 2005 [1]. The rate of anthropogenic emissions to the atmosphere is also continuing to increase. In 1950, anthropogenic emissions of $\mathrm{CO}_{2}$ were around $6 \mathrm{Gt}$ of $\mathrm{CO}_{2}$; in 2000, this number was around $22 \mathrm{Gt}^{\mathrm{CO}_{2}}$ /year; and in 2015 the number was estimated to be approximately $37 \mathrm{Gt} \mathrm{CO}_{2}$ /year [2]. From this amount, approximately $45 \%$ of the emitted anthropogenic carbon remains in the atmosphere, and the other $55 \%$ goes into the ocean and land biomass [2]. Therefore, to mitigate the effects on climate change, $\mathrm{CO}_{2}$ emissions to the atmosphere should be reduced, and the concentration of $\mathrm{CO}_{2}$ needs to be stabilized at around $450 \mathrm{ppm}$ by 2050 [1]. One attractive option for reducing $\mathrm{CO}_{2}$ emissions is carbon capture and storage (CCS) [1]. CCS involves capturing $\mathrm{CO}_{2}$ from energy related sources such as large industrial plants, transporting it to a suitable storage location and storing it in deep geological formations, before it is emitted to the atmosphere.

Among the proposed CCS options, sequestration in deep saline aquifers appears to be the most promising option due to the relatively larger storage capacity and worldwide distribution of these formations [1]. Deep saline aquifers are permeable layers (usually found in sedimentary basins), saturated with salt water and bounded from below and above by less permeable rocks. Proper analysis 
of $\mathrm{CO}_{2}$ storage in deep saline aquifers requires understanding of the properties of carbon dioxide and other fluids involved in the system, as well as properties of the geological formations. For temperatures greater than $T_{c}=31.1{ }^{\circ} \mathrm{C}$ and pressures greater than $P_{c}=7.38 \mathrm{MPa}$ (critical point), $\mathrm{CO}_{2}$ is in the supercritical state. The depth of $\mathrm{CO}_{2}$ injection in sedimentary basins is usually considered sufficiently deep to maintain the $\mathrm{CO}_{2}$ in a supercritical state.

Trapping of carbon dioxide in saline aquifers can be broadly classified into structural/stratigraphic, residual, solubility, and mineral trapping mechanisms. Structural/stratigraphic trapping refers to the processes in which $\mathrm{CO}_{2}$ is trapped in free phase under a geological structure such as an impermeable layer [3]. In this case, $\mathrm{CO}_{2}$ could be mobile but trapped since an impermeable layer prevents upward migration of $\mathrm{CO}_{2}$. In residual trapping, $\mathrm{CO}_{2}$ is stored as an immobile phase due to capillary forces and relative permeability hysteresis. In a longer period of time, solubility and mineral trapping contribute in reduction of the free phase $\mathrm{CO}_{2}$. Carbon dioxide storage is likely secure in the cases of residual trapping as well as mineral and dissolution trapping. However, in the case where $\mathrm{CO}_{2}$ is in structural/stratigraphic traps, buoyancy will always act to drive free and mobile $\mathrm{CO}_{2}$ upward and, if $\mathrm{CO}_{2}$ encounters a high permeable pathway, it will leak into the overlying formation (e.g., shallower groundwater or atmosphere) which might cause serious environmental impacts such as contamination of groundwater resources used for agricultural, industrial or human consumption, or might be a risk to vegetation, animal and human life [1].

Two approaches are commonly considered to study sequestration processes. The first approach involves long-term (century-to-millennium) processes such as dissolution of $\mathrm{CO}_{2}$ in the aquifer brine and geochemical mineralization of $\mathrm{CO}_{2}$. These studies focus on the convective dissolution and mineral trapping of carbon dioxide. Emami-Meybodi et al. [4] provided a complete review of convective mixing as a result of $\mathrm{CO}_{2}$ dissolution at the interface between the $\mathrm{CO}_{2}$ plume and the underlying brine. The second approach involves short time scales (during injection and shortly after $\mathrm{CO}_{2}$ injection is ceased) and uses the principles of two-phase flow in porous media. It considers supercritical $\mathrm{CO}_{2}$ and brine as two immiscible fluid phases, which can be described by relative permeability and capillary pressure relationships. In this study, we focus on the second approach and ignore the dissolution to investigate the processes and driving forces that are active on relatively short time scales after $\mathrm{CO}_{2}$ injection.

Migration of a buoyant fluid in a porous medium as a gravity current has received considerable attention for quite some time. In an early study, Bear [5] derived a sharp interface model for displacement of one fluid by another fluid with different densities and viscosities in a tilted confined porous layer, with background flow. More recently, Nordbotten et al. [6] studied the injection of $\mathrm{CO}_{2}$ into a saline aquifer and derived an analytical solution for evolution of $\mathrm{CO}_{2}$ plume during injection through a single well, into a horizontal and homogeneous aquifer. They defined a gravity number that expresses the ratio of buoyancy to viscous forces as $2 \pi \Delta \rho g k \lambda_{w} H^{2} / Q$, where $\Delta \rho$ is the density difference between formation brine and $\mathrm{CO}_{2}$ at in-situ condition, $k$ is the aquifer permeability, $\lambda_{w}$ is brine mobility (defined as $\lambda_{w}=k_{r w} / \mu_{w}$ ) and $H$ and $Q$ are aquifer thickness and injection rate at the in-situ condition. Other analytical solutions are available in the literature which describe the evolution of supercritical $\mathrm{CO}_{2}$ plume during injection into deep saline aquifers [7-9]. Depending on the parameters used in non-dimensionalizing the flow equations, different expressions for gravity number can be derived. For example, Ide et al. [10] used another expression for gravity number to define ratio of gravity to viscous forces as $k_{\mathrm{v}} L \Delta \rho g / H u \mu_{w}$, where $k_{\mathrm{v}}$ is vertical permeability, $L$ is the aquifer length and $u$ is the total average Darcy velocity. They performed simulations to study immobilization of $\mathrm{CO}_{2}$ plume by capillary trapping and concluded that the amount of injected $\mathrm{CO}_{2}$ that can be immobilized by residual trapping is a strong function of the gravity number, where the total amount of the trapped gas decreases as gravity number increases. They also showed that capillary pressure and aquifer tilt angle affect the value and the rate of trapping.

Kopp et al. [11,12] through dimensional analysis showed that the balance between driving forces control the displacement of $\mathrm{CO}_{2}$ plume in an aquifer during $\mathrm{CO}_{2}$ injection. They reported 
dimensionless gravitational and capillary numbers and examined their effects on storage capacity of reservoirs. They showed that a low ratio of gravitational to viscous forces (low gravitational number) and to a lesser extent a high ratio of capillary to viscous forces (high capillary number) leads to a higher $\mathrm{CO}_{2}$ storage capacity.

Possible leakage pathways could be in the form of natural interruptions and breaches through the confining strata such as open faults, fractures and erosional channels, or they could be in the form of manmade or artificial pathways such as abandoned wells or activated faults and fractures [13,14].

Figure 1 shows pathways for $\mathrm{CO}_{2}$ migration for a possible leakage. Inactive faults can be reactivated because of local pressure changes during $\mathrm{CO}_{2}$ injection. Likewise, closed fractures may open by exceeding bottom hole pressure from the minimum in-situ stress. There is an active debate on whether injection of $\mathrm{CO}_{2}$ will trigger large earthquakes and reactivate faults and therefore threaten the seal integrity of $\mathrm{CO}_{2}$ storage reservoirs $[15,16]$. The main geomechanical aspects affecting the integrity of the $\mathrm{CO}_{2}$ storage sites have been reviewed by different researchers [17,18]. For large scale injection operations, domains in the order of thousands of square kilometers need to be analyzed to guarantee the safety of storage [19].

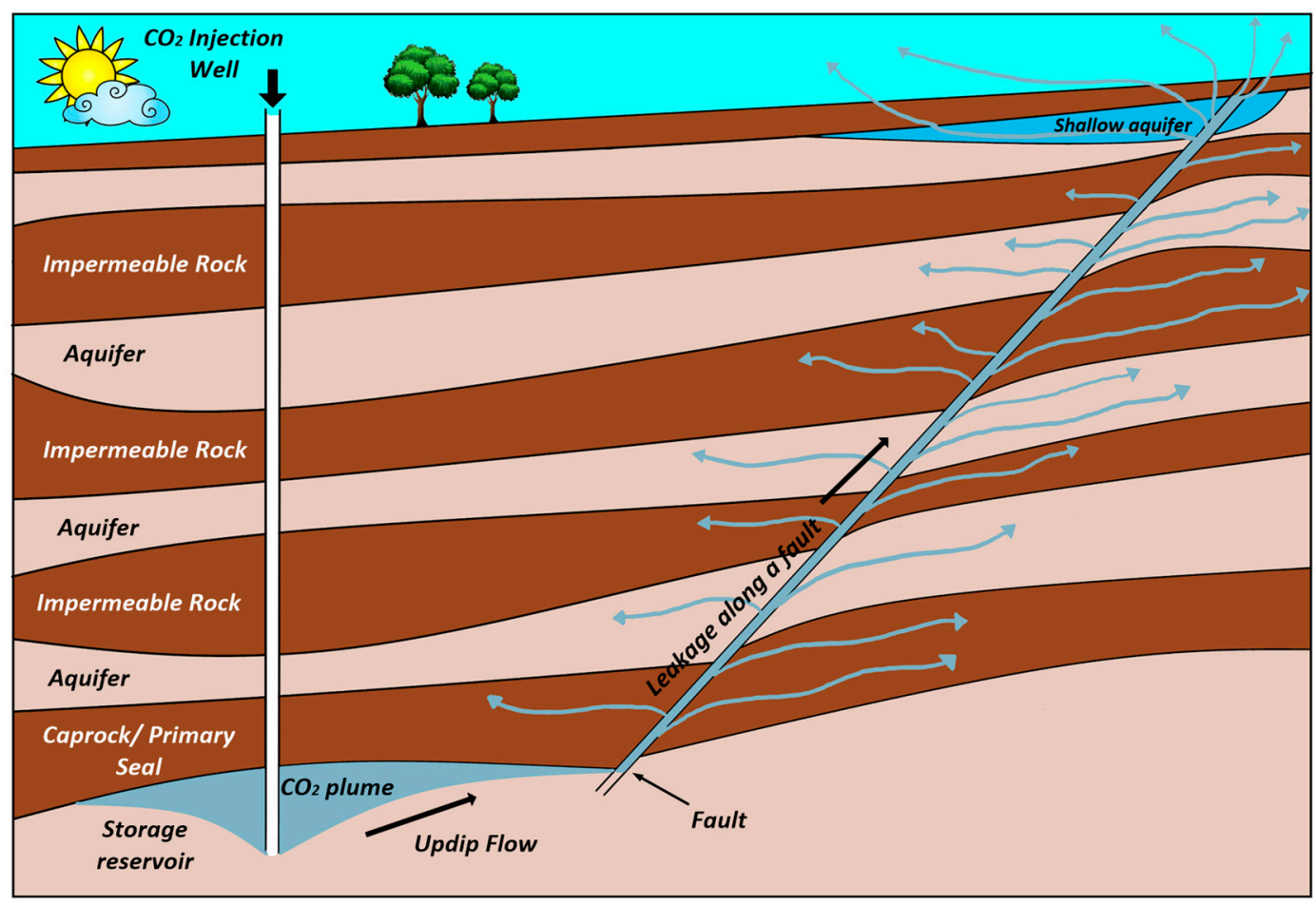

Figure 1. Pathways for $\mathrm{CO}_{2}$ migration for a possible leakage through faults (Adapted from Bachu and Celia [13]).

Leakage of $\mathrm{CO}_{2}$ can be assessed by means of numerical and analytical models. Analytical solutions can only be derived with sufficient restrictive assumptions. Various analytical solutions have been published in the literature, especially for the leakage along existing wells [20-22]. Additionally, theoretical models are developed for investigating diffusive leakage of brine from an aquifer into overburden and underburden formations during geological storage of $\mathrm{CO}_{2}[23,24]$. Although several efforts have been devoted to assess the risk of leakage through existing wells, leakage through faults and fractures has been less addressed in the literature, and it is partly due to the difficulty in characterizing the features of such pathways. Useful numerical simulations for $\mathrm{CO}_{2}$ leakage through existing/activated faults have been published in the literature [25-28]. Recently, Kang et al. [29] used a simplified model to derive expressions for pressure drawdown and interface upconing around a 
leaky fault. They described a vertical two-phase flow along a fault and concluded that, for estimation of leakage, structures and properties of the fault must be included in the model.

Even with large potential capacity of saline aquifers, a major obstacle to implement $\mathrm{CO}_{2}$ sequestration in such formations is the lack of insights into the risks associated with it. In relatively short time scales, $\mathrm{CO}_{2}$ injected into saline aquifer is in free phase and prone to leakage. Therefore, for selection of storage sites, it is important to know, in case of a leaky fault or fracture, how much $\mathrm{CO}_{2}$ will leak and how long it will take to happen. The combined effect of different mechanisms and their evolution with time and space can only be evaluated through sophisticated numerical simulations. The objective of this paper is to develop a simple model which allows for quick and relatively easy screening of storage reservoirs by investigating processes and driving forces that are active on $\mathrm{CO}_{2}$ plume in relatively short time scales after $\mathrm{CO}_{2}$ injection.

\section{Model Description and Governing Equations}

To study migration of $\mathrm{CO}_{2}$ along a water-saturated fault zone, a one-dimensional (1D) model is developed. To provide conservative estimates of the leakage potential, we ignore the effect of dissolution trapping and the system is assumed to be isothermal.

$\mathrm{CO}_{2}$ (non-wetting phase) and formation brine (wetting phase) are assumed to be immiscible and the interphase transfer between phases (mass transfer between the fluids, i.e., dissolution of $\mathrm{CO}_{2}$ in brine and evaporation of brine into $\mathrm{CO}_{2}$ ) is neglected.

Mass conservation equation and the extended Darcy formula are the governing equations of two immiscible fluids flow in porous layer for a linear system which can be written separately for each phase. The modified Darcy's law for multi-phase flow, which relates the volumetric flux of each phase to the respective phase pressure, can be written as [5]:

$$
\overrightarrow{\mathbf{v}}_{\alpha}=-\frac{k k_{r \alpha}}{\mu_{\alpha}}\left(\nabla p_{\alpha}+\rho_{\alpha} g \nabla z\right)=-k \lambda_{\alpha}\left(\nabla p_{\alpha}+\rho_{\alpha} g \nabla z\right) \quad \alpha=w, n w
$$

where $\overrightarrow{\mathbf{v}}_{\alpha}$ is the Darcy velocity [LT ${ }^{-1}$ ] of phase $\alpha, k$ is the absolute (intrinsic) permeability [L ${ }^{2}$ ] of the formation, $k_{r \alpha}$ is the relative permeability of phase $\alpha, \mu_{\alpha}$ is the viscosity $\left[\mathrm{ML}^{-1} \mathrm{~T}^{-1}\right.$ ] of phase $\alpha, p_{\alpha}$ is

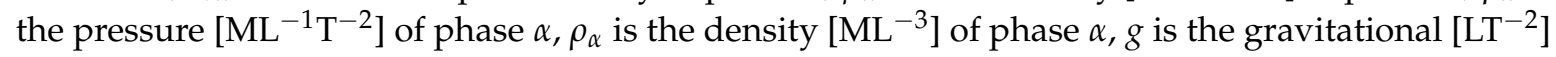
acceleration, $z$ is the vertical coordinate [L] and positive upward, and $\lambda_{\alpha}=k_{r \alpha} / \mu_{\alpha}$ is the mobility of phase $\alpha$.

Mass balance equation for each phase is given by [5]:

$$
\frac{\partial\left(\phi \rho_{\alpha} S_{\alpha}\right)}{\partial t}+\nabla \cdot\left(\rho_{\alpha} \overrightarrow{\mathbf{v}}_{\alpha}\right)-\rho_{\alpha} q_{\alpha}=0 \quad \alpha=w, n w
$$

where $\phi$ is formation porosity and $q_{\alpha}$ represents source/sink term $\left[\mathrm{T}^{-1}\right]$. By substitution of Equation (1) into Equation (2), a system of partial differential equations is obtained for each phase.

Additional closure equations are required to solve the system of the partial differential equations. First, the sum of phase saturations equals unity.

$$
\sum_{\alpha} S_{\alpha}=1
$$

Second, the pressure difference between the two phases equals capillary pressure $p_{c}$ [5]:

$$
p_{c}=p_{n w}-p_{w}
$$

Finally, to solve the system of partial differential equations, constitutive relations are required, which include capillary pressure and relative permeability as functions of saturation. In this study, the following assumptions have been made to simplify the modeling of two-phase flow. The porous 
layer (leakage pathway) is considered homogenous, isotropic and one-dimensional tilted with an angle $\theta$ from the horizontal axis. Formation brine $(w)$ and gas/supercritical phase $(n w)$ are single-component fluids and are assumed to be incompressible. The flow is considered isothermal, sources and sinks are not present and the dynamic viscosity is also assumed to be constant. These assumptions allow development of a simple and fast model for analysis of leakage and have been previously used in many studies. Nevertheless, modeling of $\mathrm{CO}_{2}$ leakage from leakage pathways in the absence of these assumptions requires detailed geological and numerical models. Simulation of $\mathrm{CO}_{2}$ leakage including all details, such as 3D features, pathway heterogeneities, phase behavior and phase change, geomechanical effects, thermal, and geochemical effects, is very time consuming and difficult, if not impossible. In addition, simple models often provide a first order estimate of $\mathrm{CO}_{2}$ leakage necessary for site screening and risk assessment. A schematic of the problem is shown in Figure 2.

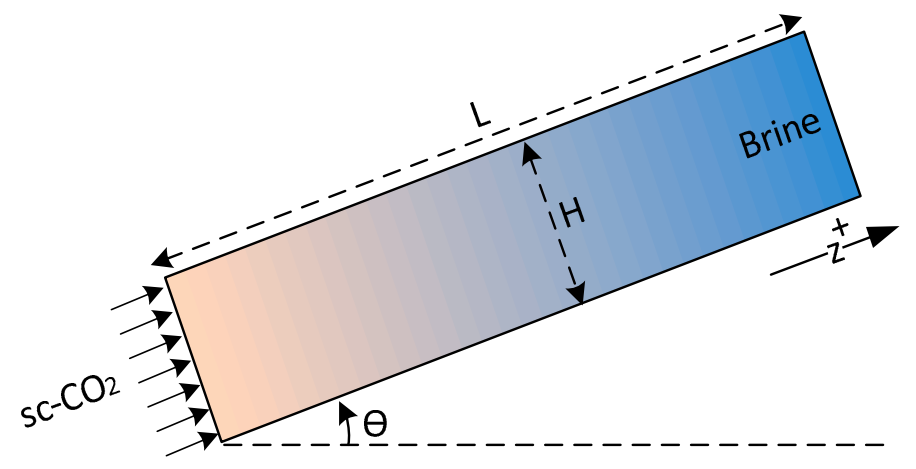

Figure 2. Schematic of the problem.

Using the above-mentioned assumptions and adding the definition of capillary pressure (Equation (4)), $\mathrm{CO}_{2}$ flux can be written as:

$$
\mathbf{v}_{n w}=\frac{k \lambda_{n w} \lambda_{w}}{\lambda_{t}}\left[-\frac{d p_{c}}{d S_{n w}} \frac{\partial S_{n w}}{\partial z}+\Delta \rho g \sin \theta\right]+\frac{\lambda_{n w} \mathbf{v}_{t}}{\lambda_{t}}
$$

With substitution in mass balance equation, saturation equation for $\mathrm{CO}_{2}$ phase can be written as:

$$
\phi \frac{\partial S_{n w}}{\partial t}+\frac{\partial}{\partial z}\left[-\frac{k \lambda_{n w} \lambda_{w}}{\lambda_{t}} \frac{d p_{c}}{d S_{n w}} \frac{\partial S_{n w}}{\partial z}+\frac{k \lambda_{n w} \lambda_{w}}{\lambda_{t}} \Delta \rho g \sin \theta+\frac{\lambda_{n w}}{\lambda_{t}} \mathbf{v}_{t}\right]=0
$$

where $\mathbf{v}_{t}=\mathbf{v}_{n w}+\mathbf{v}_{w}$ is constant total velocity and is defined as the summation of $\mathrm{CO}_{2}$ and brine velocities. In addition, $\lambda_{t}=\lambda_{n w}+\lambda_{w}$ and $\Delta \rho=\rho_{w}-\rho_{n w}$ are total mobility and density difference, respectively.

Equation (6) is a second-order nonlinear partial differential equation, which is of the general form for describing flow of two immiscible incompressible fluids in a one-dimensional porous media. To develop the dimensionless form of Equation (6), the following dimensionless variables are defined.

$$
\begin{gathered}
S=\frac{S_{n w}-S_{c c}}{1-S_{w r}-S_{c c}} \\
z_{D}=\frac{z}{l_{c r}} \\
t_{D}=\frac{t}{t_{c r}} \\
t_{c r}=\frac{\phi^{*} l_{c r}}{\mathbf{v}_{t}}
\end{gathered}
$$

where $\phi^{*}=\phi\left(1-S_{w r}-S_{c c}\right)$. 
In the above equations, $S$ is the normalized gas saturation varying between 0 and $1, S_{w r}$ is the irreducible (or residual) saturation of brine, and $S_{c c}$ is the critical gas saturation. Fluid saturations are often normalized with respect to the ranges of values occurring in the problem under consideration. $1-S_{w r}$ and $S_{c c}$ are the maximum and minimum saturations that occur during the migration of $\mathrm{CO}_{2}$, respectively. Dimensionless variables $z_{D}$ and $t_{D}$ are dimensionless length and time $\left(0 \leq z_{D} \leq 1, t_{D} \geq 0\right)$, respectively. Parameters $l_{c r}$ and $t_{c r}$ are the characteristic values for length and time, respectively. Choosing the correct characteristic scale is of great importance and requires a well-developed understanding of the system being analyzed since it can change the dimensionless numbers (see Section 3.1) by orders of magnitudes [11]. In this study, the total length of the system is used to scale the migration length $\left(l_{c r}=L\right)$ and $t_{c r}$ is the time at which the migrating $\mathrm{CO}_{2}$ travels the length of the system by pure advection.

With substitutions, the dimensionless velocity of $\mathrm{CO}_{2}\left(\mathbf{v}_{D}\right)$ is obtained as:

$$
\mathbf{v}_{D}=\frac{\mathbf{v}_{n w}}{\mathbf{v}_{t}}=-\frac{k \lambda_{n w} \lambda_{w}}{L \mathbf{v}_{t} \lambda_{t}} \frac{d p_{c}}{d S} \frac{\partial S}{\partial z_{D}}+\frac{k \lambda_{n w} \lambda_{w}}{\mathbf{v}_{t} \lambda_{t}} \Delta \rho g \sin \theta+\frac{\lambda_{n w}}{\lambda_{t}}
$$

and the gas saturation equation (Equation (6)) therefore can be written as:

$$
\frac{\partial S}{\partial t_{D}}+\frac{\partial}{\partial t_{D}}\left(-\frac{k \lambda_{n w} \lambda_{w}}{L \mathbf{v}_{t} \lambda_{t}} \frac{d p_{c}}{d S} \frac{\partial S}{\partial z_{D}}+\frac{k \lambda_{n w} \lambda_{w}}{\mathbf{v}_{t} \lambda_{t}} \Delta \rho g \sin \theta+\frac{\lambda_{n w}}{\lambda_{t}}\right)=0
$$

To determine solution of Equation (12), proper saturation functions for capillary pressure and relative permeability are required. In this study, the following relative permeability relations as function of saturation are used in the form of Brooks-Corey equation [30].

$$
\begin{gathered}
k_{r n w}=k_{r n w}^{\max }(S)^{n c} \\
k_{r w}=k_{r w}^{\max }(1-S)^{n b}
\end{gathered}
$$

In the above equation, $k_{r n w}^{\max }$ is the relative permeability of $\mathrm{CO}_{2}$ at irreducible brine saturation, and $k_{r w}^{\max }$ is the relative permeability to brine at the critical $\mathrm{CO}_{2}$ saturation. For the drainage cycle, $k_{r w}^{\max }=1$ and $S_{c c}=0$. Parameters $n c$ and $n b$ are the constants (also known as Corey's coefficients), which affect the shape of the relative permeability curves. Increasing values of these coefficients cause the relative permeability curve to become concave. The capillary pressure is represented by a logarithmic function, which has been conventionally used for such problems [31].

$$
p_{c}=-p_{d} \ln (1-S)
$$

where $p_{d}$ is the capillary entry pressure.

Different dimensionless numbers can be established to define the balance between driving forces taking place during and after $\mathrm{CO}_{2}$ injection. For the $\mathrm{CO}_{2}$ injection application, Kopp et al. [11] used dimensionless capillary and gravitational numbers and qualitatively examined their effects on storage capacity. Here, we use a similar form of dimensionless numbers for our system.

Substitution of Equations (13)-(15) into Equations (11) and (12) gives:

$$
\begin{gathered}
\mathbf{v}_{D}=\underbrace{-N_{C a} D(S) \frac{\partial S}{\partial z_{D}}}_{\mathbf{v}_{D D}}+\underbrace{N_{G r} G(S)}_{\mathbf{v}_{D G}}+\underbrace{V(S)}_{\mathbf{v}_{D V}} \\
\frac{\partial S}{\partial t_{D}}+\frac{\partial}{\partial z_{D}}\left[-N_{C a} D(S) \frac{\partial S}{\partial z_{D}}+N_{G r} G(S)+V(S)\right]=0
\end{gathered}
$$

where $\mathbf{v}_{D D}, \mathbf{v}_{D G}$ and $\mathbf{v}_{D V}$ are capillary, gravity and viscous contribution to dimensionless $\mathrm{CO}_{2}$ velocity, respectively. $N_{C a}$ is the dimensionless capillary number and $N_{G r}$ is the dimensionless gravity number, 
which relate forces acting on the system and are analyzed based on the reservoir parameters as well as fluid properties as follow.

$$
\begin{gathered}
N_{C a}=\frac{k k_{r n w}^{\max } p_{d}}{L \mu_{n w} \mathbf{v}_{t}} \quad \frac{\text { Capillary Forces }}{\text { Viscous Forces }} \\
N_{G r}=\frac{k k_{r n w}^{\max } \Delta \rho g \sin \theta}{\mu_{n w} \mathbf{v}_{t}} \quad \text { Gravity Forces } \\
\text { Viscous Forces }
\end{gathered}
$$

$D(S), G(S)$ and $V(S)$ are capillary, gravity and viscous functions, respectively, and are defined as:

$$
\begin{aligned}
& D(S)=\frac{S^{n c}(1-S)^{n b-1}}{M S^{n c}+(1-S)^{n b}} \quad \text { Capillary Function } \\
& G(S)=\frac{(S)^{n c}(1-S)^{n b}}{M(S)^{n c}+(1-S)^{n b}} \quad \text { Gravity Function } \\
& V(S)=\frac{M(S)^{n c}}{M(S)^{n c}+(1-S)^{n b}} \quad \text { Viscous Function }
\end{aligned}
$$

where

$$
M=\frac{k_{r n w}^{\max } / \mu_{n w}}{k_{r w}^{\max } / \mu_{w}} \quad \text { Mobility Ratio }
$$

Equation (17) is used to simulate $\mathrm{CO}_{2}$ migration in a linear porous media and considers viscous, capillary and gravity forces simultaneously. Equation (17) is a nonlinear second order partial differential equation, which is also known as nonlinear convection-diffusion equation. A similar form of this equation has been developed before for the application of water flooding in oil reservoirs [32]. The first term in Equation (17) is the accumulation term; the second term includes the contribution of capillary forces in the displacement process and has a diffusive nature; the third term contains the gravitational contributions to the flow and has an advective character; and the fourth term is the contribution of viscous forces and same as the third term has an advective character.

The problem described by Equation (17) is completed by setting proper initial and boundary conditions. In this study, we assume that the entire domain is initially fully saturated with brine, therefore only primary drainage process is considered here, and the residual $\mathrm{CO}_{2}$ is not a concern. At the inlet boundary, it is considered that $\mathrm{CO}_{2}$ saturation is always at its maximum value. This assumption seems reasonable when $\mathrm{CO}_{2}$ has already displaced the formation brine beneath a leakage pathway and a residual saturation of the wetting phase has been established. At the outlet boundary it is assumed that the changes in $\mathrm{CO}_{2}$ saturation is negligible. This boundary condition infers negligible diffusive (capillary) flux at the outer boundary compared to gravity and viscous fluxes. The initial and boundary conditions are then given by:

$$
\begin{array}{cc}
t_{D}=0 & S=0 \\
z_{D}=0 & S=1 \\
z_{D}=1 & \frac{\partial S}{\partial z_{D}}=0
\end{array}
$$

The model described above forms the basis of this study. Numerical discretization and detailed validation of the developed model is presented in Appendices A and B, respectively.

\section{Results and Discussion}

The developed model in the previous section is utilized to understand processes and driving forces active during leakage of $\mathrm{CO}_{2}$ into the shallower formations. This section is organized as follows. First, the effect of dimensionless numbers and interaction of forces on the displacement process and 
leakage is investigated. Next, the developed model is used to assess leakage in seven formations located in Alberta, Canada, which are considered potential options for geological storage of $\mathrm{CO}_{2}$.

\subsection{Interaction of Gravity, Capillary, and Viscous Forces}

To investigate the effect of forces acting on the fluid flow and rate of leakage, we define seven different datasets. Detailed comparison and properties of each set is presented in Table 1 . The following properties are assumed to be the same for all the seven datasets. Length of the domain $(L)$ is considered to be $500 \mathrm{~m}$. Density difference between $\mathrm{CO}_{2}$ and brine $\left(\Delta \rho=\rho_{w}-\rho_{n w}\right)$ is assumed to be $300 \mathrm{~kg} / \mathrm{m}^{3}$ and porosity $(\phi)$ is 0.2 . Brine and $\mathrm{CO}_{2}$ viscosity are assumed to be 0.86 and $0.06 \mathrm{mPa} \cdot \mathrm{s}$, respectively. Absolute permeability is taken to be $100 \mathrm{mD}$ and residual water saturation $\left(S_{w r}\right)$ is assumed to be 0.3. Parameters used for these datasets are only for comparison and they are not related to a specific reservoir. The last three rows in Table 1 show the calculated mobility ratio, $N_{C a}$ and $N_{G r}$. Dataset 1 is considered as base case. In each dataset, the changing parameter is bolded in Table 1. Two analysis groups have been established. First, the effect of changes in $N_{C a}$ and $N_{G r}$ is investigated, while $D(S)$, $G(S)$ and $V(S)$ are kept constant (Datasets 2-4). Second, changes of relative permeability parameters of $\mathrm{CO}_{2}$ and brine system are examined, which include the effect of mobility ratio and Corey exponents $n b$ and $n c$ (Datasets 5-7). Changes in gas saturation profile and gas dimensionless velocity are examined for each dataset. Breakthrough time is considered to be the time when migrating $\mathrm{CO}_{2}$ appears at the outlet boundary.

Figure 3 shows the parameters map of $N_{G r}-N_{C a}$ space. A reference equilibrium state between gravitational and viscous forces is indicated with dotted line at $N_{G r}=1$ and between capillary and viscous forces at $N_{C a}=1$. In Figure 3 , the lower left sector represents domination of viscous forces over capillary and gravitational forces. As we move from this sector to the right or top, viscous forces lose their influence in favor of capillary (lower right sector) or gravitational (upper left sector) forces, respectively. Finally, in the upper right sector, capillary and gravitational forces dominate over viscous forces.

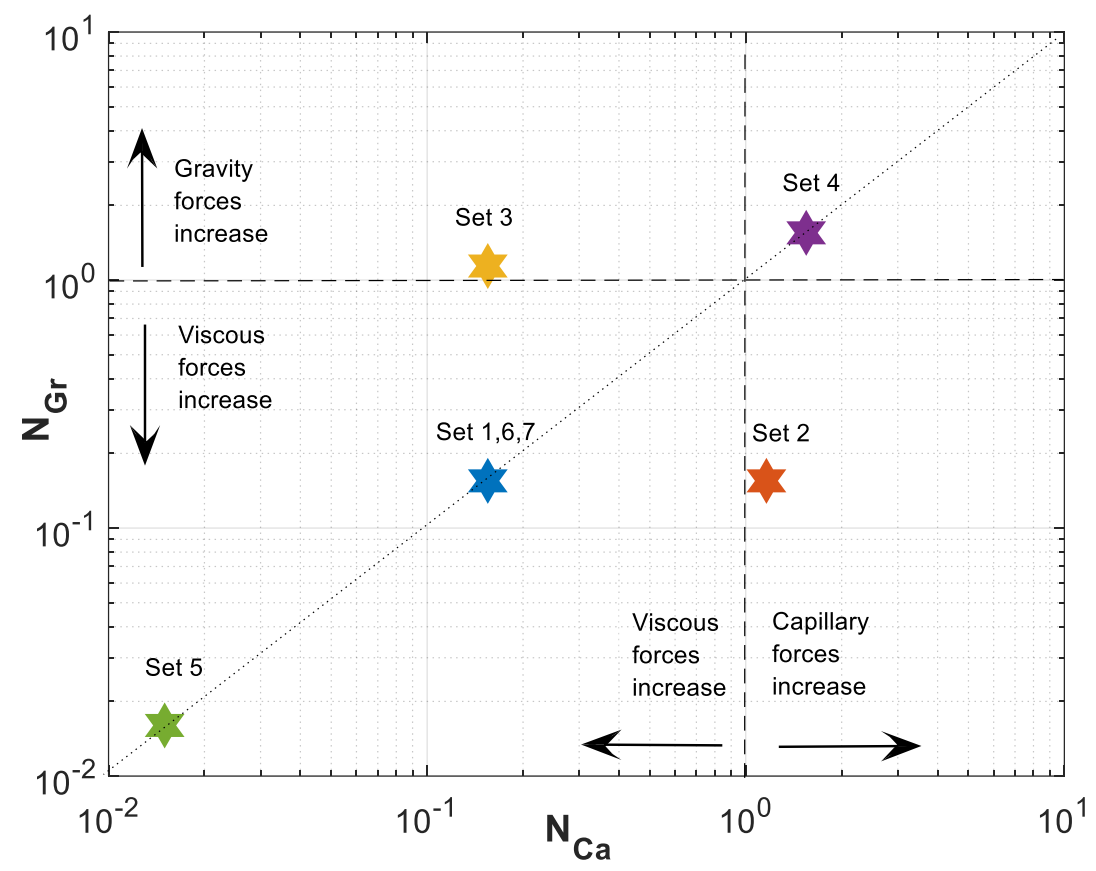

Figure 3. Gravity number, $N_{G r}$, versus capillary number, $N_{C a}$, for Datasets 1-7 defined in Table 1. 
Table 1. Simulation parameters used in qualitative analysis.

\begin{tabular}{cccccccc}
\hline Data & Dataset 1 & Dataset 2 & Dataset 3 & Dataset 4 & Dataset 5 & Dataset 6 & Dataset 7 \\
\hline Capillary entry pressure, $p_{d}(\mathrm{MPa})$ & 0.2 & $\mathbf{1 . 5}$ & 0.2 & 0.2 & 0.2 & 0.2 & 0.2 \\
Tilt angle, $\theta$ & $\pi / 23$ & $\pi / 23$ & $\pi / 2$ & $\pi / 23$ & $\pi / 23$ & $\pi / 23$ & $\pi / 23$ \\
Total velocity, $\mathbf{v}_{t}(\mathrm{~m} / \mathrm{s})$ & $3 \times 10^{-6}$ & $3 \times 10^{-6}$ & $3 \times 10^{-6}$ & $\mathbf{3} \times \mathbf{1 0}^{-7}$ & $3 \times 10^{-6}$ & $3 \times 10^{-6}$ & $3 \times 10^{-6}$ \\
End-point rel-perm of $\mathrm{CO}_{2}, k_{r n w}^{\max }$ & 0.65 & 0.65 & 0.65 & 0.65 & $\mathbf{0 . 0 6 5}$ & 0.65 & 0.65 \\
Corey Exponent for Brine, $n b$ & 2 & 2 & 2 & 2 & 2 & $\mathbf{4}$ & 2 \\
Corey exponent for $\mathrm{CO}_{2}, n c$ & 2 & 2 & 2 & 2 & 2 & 2 & $\mathbf{4}$ \\
$M$ & 10.03 & 10.03 & 10.03 & 10.03 & 1.00 & 10.03 & 10.03 \\
$N_{C a}$ & 0.155 & 1.161 & 0.155 & 1.548 & 0.015 & 0.155 & 0.155 \\
$N_{G r}$ & 0.155 & 0.155 & 1.139 & 1.550 & 0.016 & 0.155 & 0.155 \\
\hline
\end{tabular}

Capillary, gravity and viscous functions are plotted for all seven datasets in Figure 4a-c. The shape and value of these functions are influenced by Corey exponents in relative permeability equation $(n c$ and $n b$ ), and mobility ratio. Capillary function $D(S)$ (Figure $4 \mathrm{a}$ ) and gravity function $G(S)$ (Figure $4 \mathrm{~b}$ ) have a bell shape, whereas shape of $V(S)$ is the same as the fractional flow equation in Buckley-Leveret problem.

In the first four datasets, dimensionless functions $D(S), G(S)$ and $V(S)$ are same. In Datasets 5-7, relative permeability parameters are changed to evaluate their effect on flow process. Migration of $\mathrm{CO}_{2}$ plume depends on balance of these forces, which determines the security of storage.
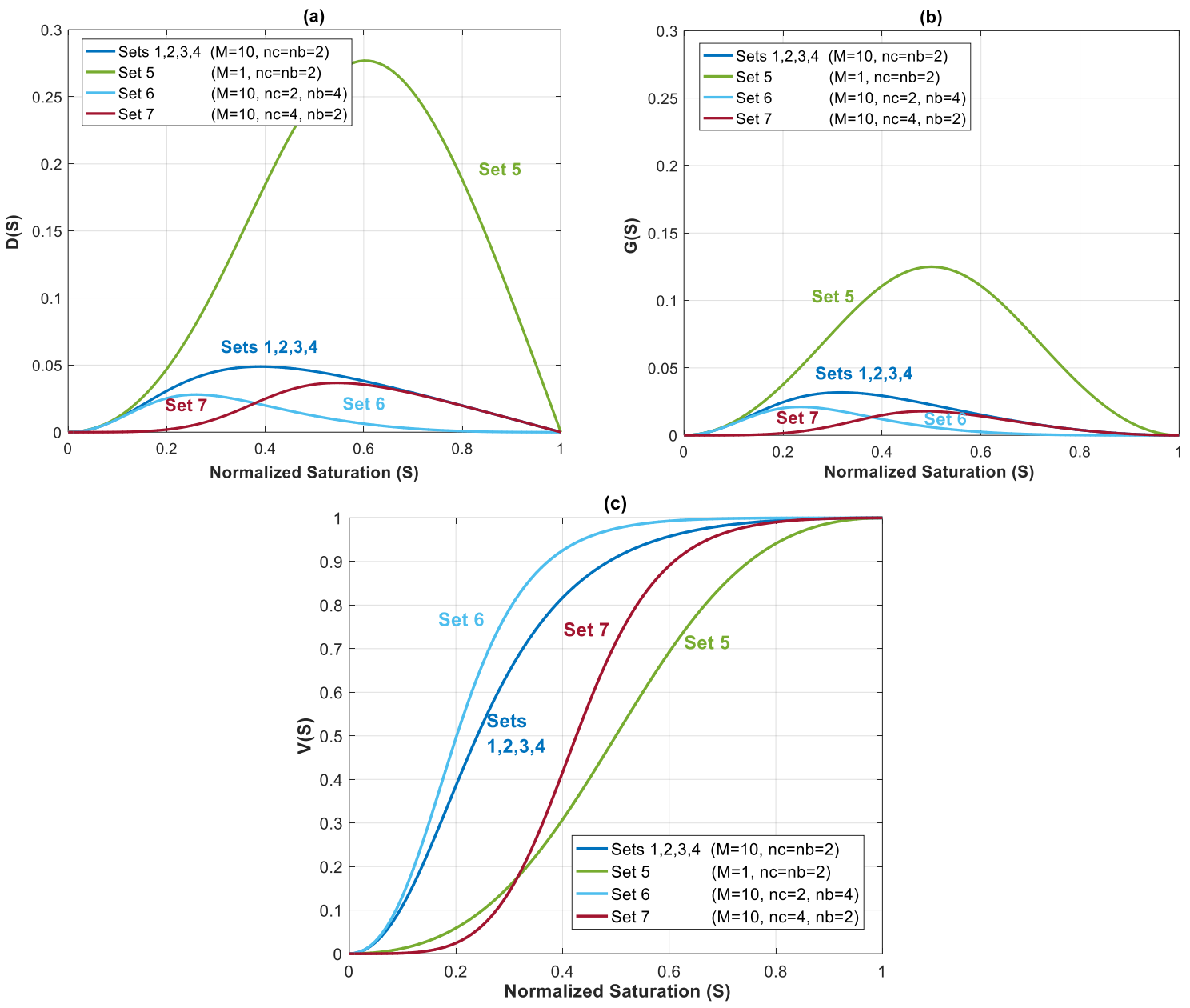

Figure 4. (a) Capillary function, $D(S)$; (b) gravity function, $G(S)$; and (c) viscous function, $V(S)$, for Datasets 1 to 7 from Table 1 . 
Figure 5 shows the normalized gas saturation and contribution of different forces in $\mathrm{CO}_{2}$ dimensionless velocity versus dimensionless length at time $t_{D}=0.2$ for Datasets 1 to 4 .
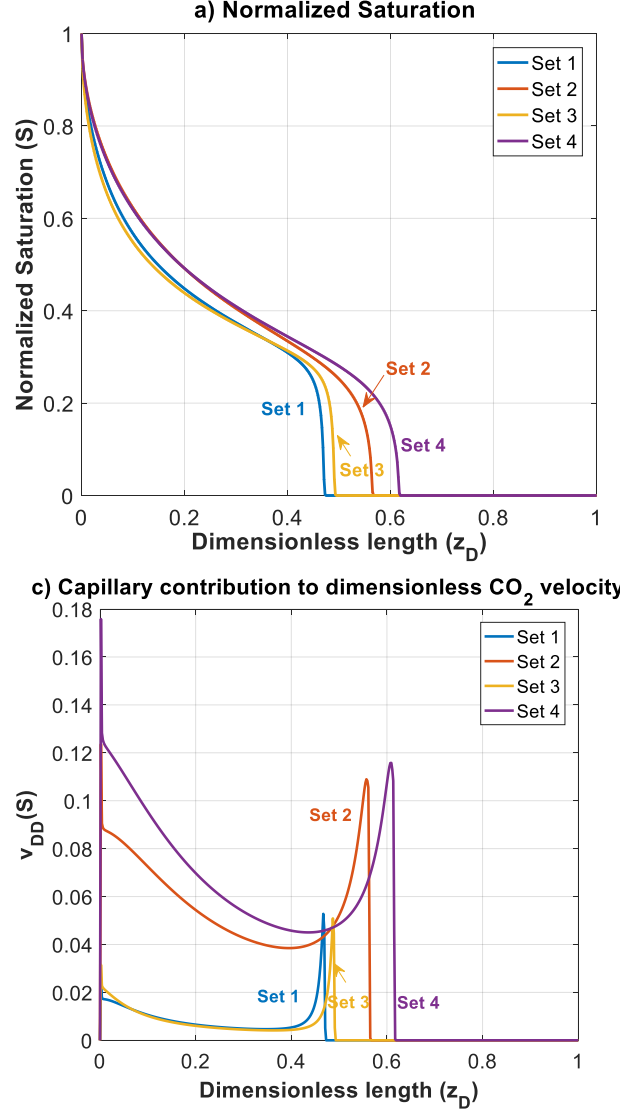

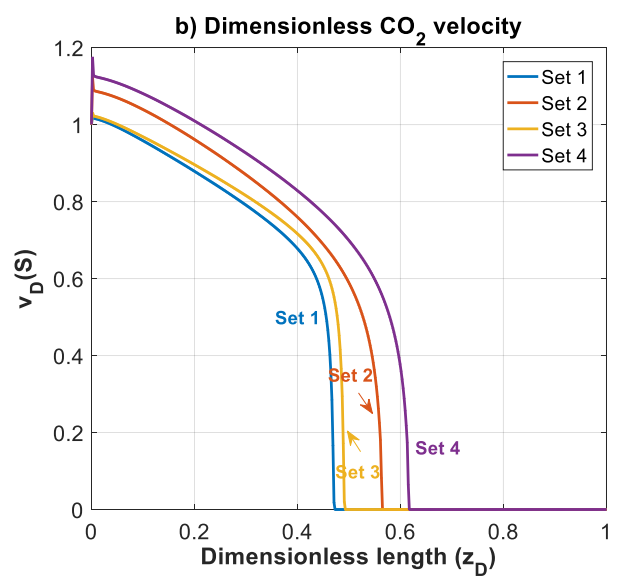

d) Gravity contribution to dimensionless $\mathrm{CO}$ velocity

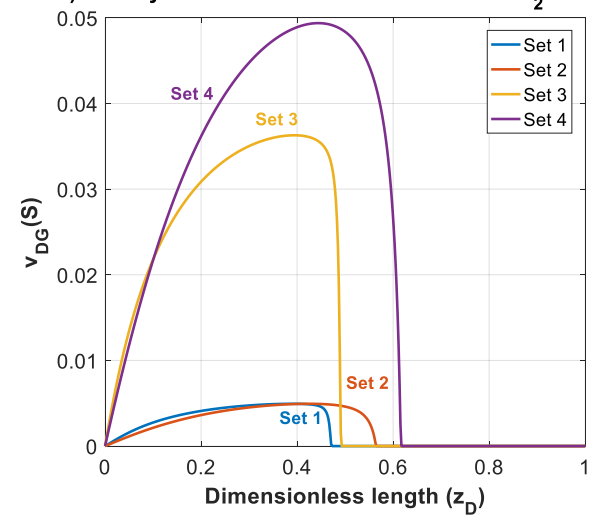

e) Viscous contribution to dimensionless $\mathrm{CO}_{2}$ velocity

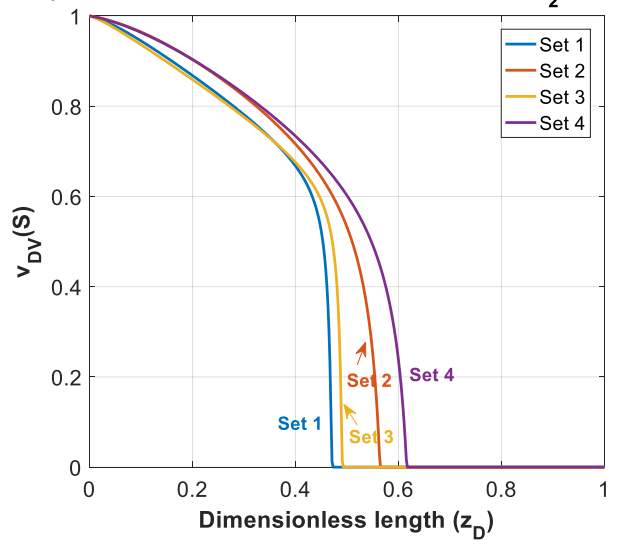

Figure 5. Normalized $\mathrm{CO}_{2}$ saturation and dimensionless $\mathrm{CO}_{2}$ velocity profiles versus dimensionless length at $t_{D}=0.2$ for Datasets 1-4 (Table 1): (a) normalized saturation; (b) dimensionless $\mathrm{CO}_{2}$ velocity, $\mathbf{v}_{D}$; (c) capillary contribution to $\mathrm{CO}_{2}$ velocity, $\mathbf{v}_{D D}$; (d) gravity contribution to $\mathrm{CO}_{2}$ velocity, $\mathbf{v}_{D G}$; and (e) viscous contribution to $\mathrm{CO}_{2}$ velocity, $\mathbf{v}_{D V}$.

For Dataset 1 (Table 1), $N_{C a}$ and $N_{G r}$ have the same magnitude and less than one, and position of this dataset in the parameter space map is in the lower left sector of Figure 3. This is translated to dominance of viscous forces over capillary and gravity forces. As shown in Figure 5, higher viscous forces lead to a $\mathrm{CO}_{2}$ plume with sharp front. As a result, plume migration is slowest among other datasets (Datasets 2-4). In this case, gravitational forces are rather weak, leading to a low buoyancy-induced upward migration of $\mathrm{CO}_{2}$. 
In Dataset 2 , the effect of capillary entry pressure, $p_{d}$, is investigated. By changing the capillary entry pressure $\left(p_{d}\right)$ from $0.2 \mathrm{MPa}$ to $1.5 \mathrm{MPa}$, capillary number $\left(N_{C a}\right)$ increases up to 1.161 , while the gravity number $\left(N_{G r}\right)$ remains the same as the one used in Dataset 1 . This leads to a shift to the lower right corner of the parameter map, as shown in Figure 3. Increasing capillary number will increase the influence of capillary forces over viscous forces. Stronger capillary forces lead to a more diffusive-like front propagation. An earlier breakthrough is a result of higher capillary forces, as shown in the saturation distributions and velocity profiles for Datasets 1 and 2 in Figure 5a,b (and later in Figure 6a). As shown in Figure $5 c$, as $N_{C a}$ increases in Dataset 2, contributions of capillary forces on $\mathrm{CO}_{2}$ plume velocity $\left(\mathbf{v}_{D D}\right)$ increases. As the effect of capillary forces increases, the inlet dimensionless velocity $\left(\mathbf{v}_{D}\right)$ of the migrating $\mathrm{CO}_{2}$ takes values greater than one. This is because the dimensionless velocity of the migrating $\mathrm{CO}_{2}$ is given by $\mathbf{v}_{D}=1-\mathbf{v}_{b} / \mathbf{v}_{t}$. At high capillary forces, there is backward flow of brine as $\mathrm{CO}_{2}$ migrates upward. This leads to $\mathbf{v}_{b}$ values to be less than zero that results in $\mathbf{v}_{D}$ values greater than one. In other words, a dimensionless velocity greater than one indicates backward flow of formation brine from the leakage pathway. This effect is particularly important in the early times and, as the plume evolves, the effect of capillary diminishes.

(a)

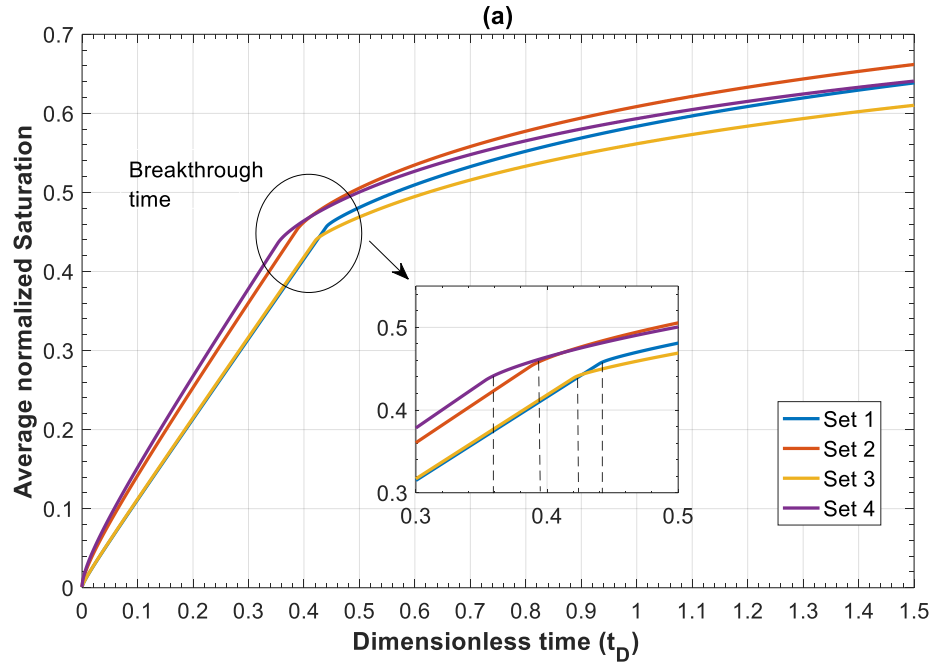

(b)

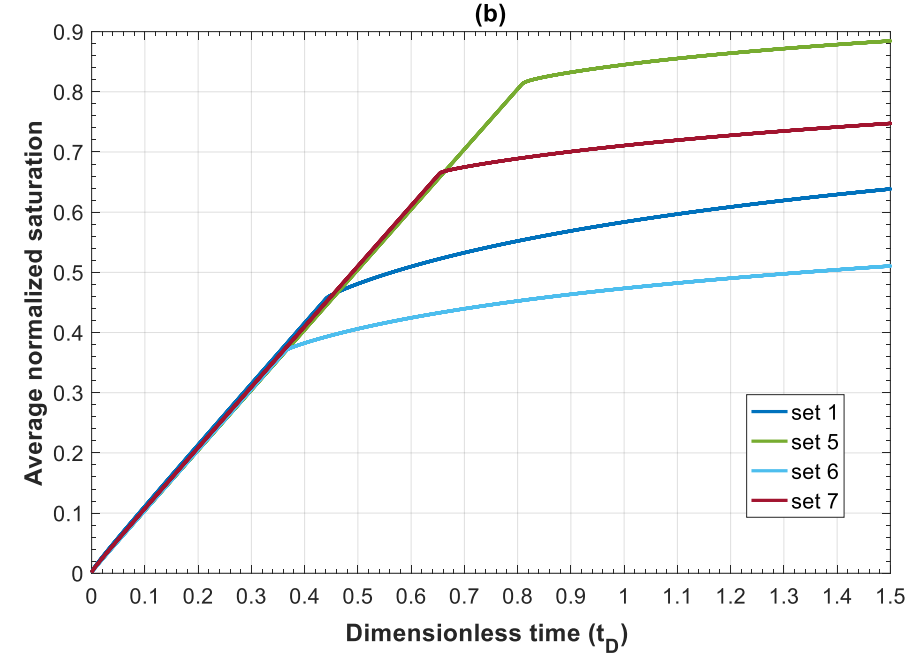

Figure 6. Average saturation versus dimensionless time $\left(t_{D}\right)$ for: (a) Datasets 1-4 (Table 1 ) to show the effect of varying $N_{C a}$ and $N_{G r}$; and (b) Datasets 1 and 5-7 (Table 1) to show the effect of relative permeability parameters $M, n c$ and $n b$.

The effect of gravitational forces is examined using Dataset 3 while $N_{C a}$ is kept similar to Dataset 1 . As the density difference or the tilt angle $(\theta)$ increase the effect of gravity on $\mathrm{CO}_{2}$ plume migration 
increases. The gravity number $\left(N_{G r}\right)$ varies up to 1.139 for a tilt angle of $\theta=\pi / 2$ (or a vertical leakage pathway). By increasing $N_{G r}$, the effect of gravity forces on dimensionless velocity $\left(\mathbf{v}_{D G}\right)$ increases and therefore a more buoyant flow regime is established leading to a faster plume evolution for Dataset 3 , compared to Dataset 1 . Such a flow regime may be preferred since it creates an extended contact between the injected $\mathrm{CO}_{2}$ and brine leading to higher dissolution of $\mathrm{CO}_{2}$ in brine. However, increasing $N_{G r}$ enhances the effect of gravity segregation and leads to an earlier breakthrough of $\mathrm{CO}_{2}$ and possibly an enhanced risk of leakage, which is not desirable.

Next, we study the effect of total Darcy velocity by changing $\mathbf{v}_{t}=3 \times 10^{-6} \mathrm{~m} / \mathrm{s}$ to a lower value of $\mathbf{v}_{t}=3 \times 10^{-7} \mathrm{~m} / \mathrm{s}$. Decreasing $\mathbf{v}_{t}$ causes an increase in both $N_{C a}$ and $N_{G r}$. However, since velocity appears in both numbers, their ratio will stay the same. This will lead to a move to the upper right corner of the parameter map shown in Figure 3. By moving to this sector, viscous forces lose their influence in favor of both capillary and gravity forces. The combined effect of increasing capillary and gravity forces will cause fastest evolution of $\mathrm{CO}_{2}$ plume compared to other datasets. In Figure 6a, the average gas saturation is plotted against dimensionless time for Datasets $1-4$. In terms of leakage, Dataset 1 results in a more compact and less diffusive front with delayed breakthrough of the leaked $\mathrm{CO}_{2}$ compared to the other cases. However, in such a case, a sudden release of $\mathrm{CO}_{2}$ is expected.

On the other hand, when capillary forces are dominant (Dataset 2), the leaking $\mathrm{CO}_{2}$ forms a diffusive front and consequently an earlier breakthrough of the gradually leaking $\mathrm{CO}_{2}$ is expected. This may be practically important since it provides more time to take remedial actions. Similarly, increasing gravity effect in Dataset 3 results in an earlier breakthrough time. It is worth mentioning that the effect of increasing $N_{G r}$ by one order of magnitude on accelerating the breakthrough time, is much less than that of increasing $N_{C a}$. Finally, for Dataset 4, the breakthrough time is the lowest among the other datasets due to domination of both capillary and gravity forces. In addition, as depicted in Figure $5 b$, increasing dimensionless velocity $\left(\mathbf{v}_{D}\right)$ to values higher than one is more pronounced in this case due to the simultaneous effect of gravity and capillary. Early leakage of brine may be used as an indicator of subsequent leakage of $\mathrm{CO}_{2}$. However, in cases such as Dataset 4, significant back flow of brine may occur, which can lead to less brine leakage prior to $\mathrm{CO}_{2}$ leakage. This effect could be emphasized especially for higher values of $N_{C a}$ and $N_{G r}$, where it could result in $\mathrm{CO}_{2}$ leakage to shallower depths without significant leakage of brine.

We further study the effect of relative permeability parameters on the displacement process. Relative permeability depends on several factors such as pore size characteristics, wettability of fluids and phase saturation [33]. Neglecting these dependencies will affect the interpretation of short and long-term fate of the injected $\mathrm{CO}_{2}$ in deep saline aquifers. Therefore, detailed laboratory measurements are necessary to predict the dependency of the relative permeability to saturation of phases present in the medium. In our model, shape of the relative permeability curve is determined by the Corey exponents and endpoint relative permeability to each phase.

In this section, effects of mobility ratio (which could be due to changes on $k_{r n w}^{\max }$ or viscosity ratio), $n b$ and $n c$ on plume migration is investigated through Datasets 5-7. These parameters affect shapes of $D(S), V(S)$ and $G(S)$ functions. For simplicity, and to illustrate the effects, we considered $n c=n b=2$ for Datasets 1-5. The normalized gas saturation and contribution of different forces on $\mathrm{CO}_{2}$ dimensionless velocity, versus dimensionless length is plotted in Figure 7 at time $t_{D}=0.2$ for Datasets 1 and 5-7. 

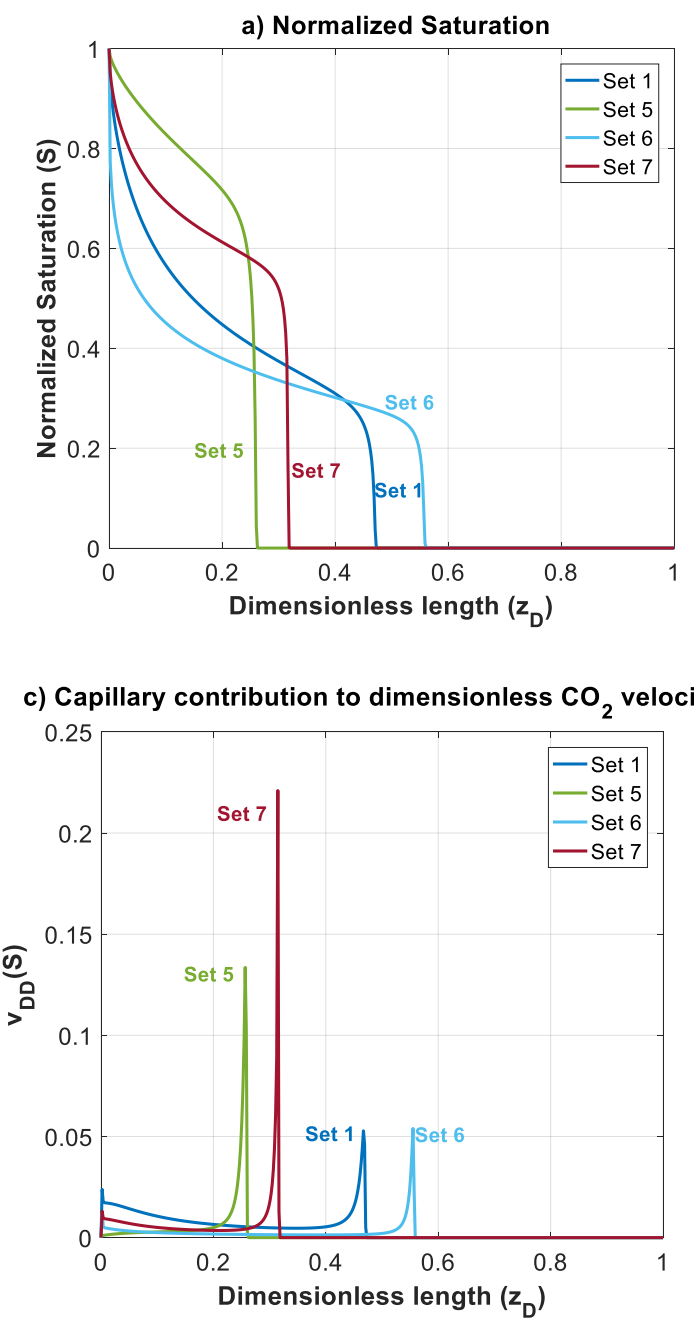

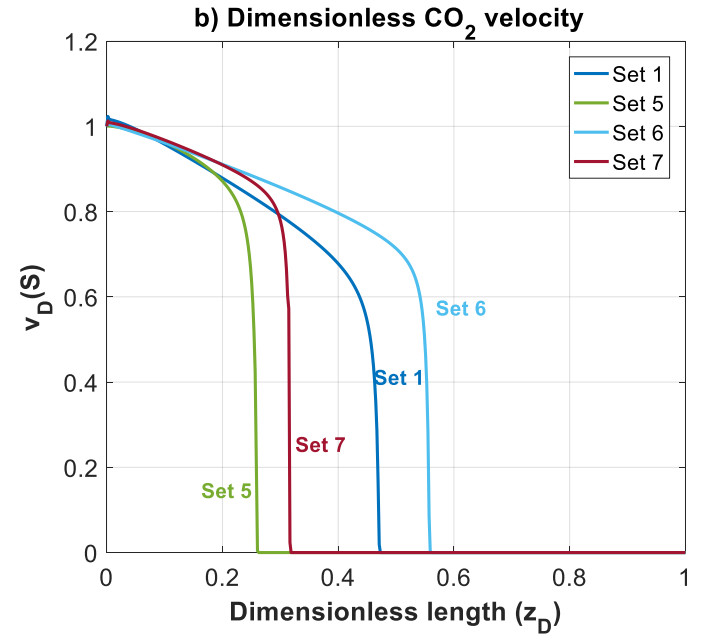

d) Gravity contribution to dimensionless $\mathrm{CO}_{2}$ velocity

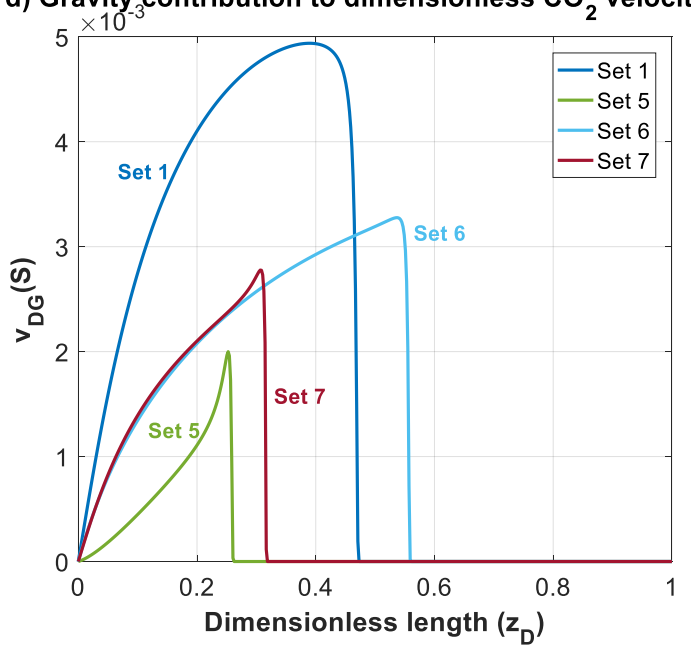

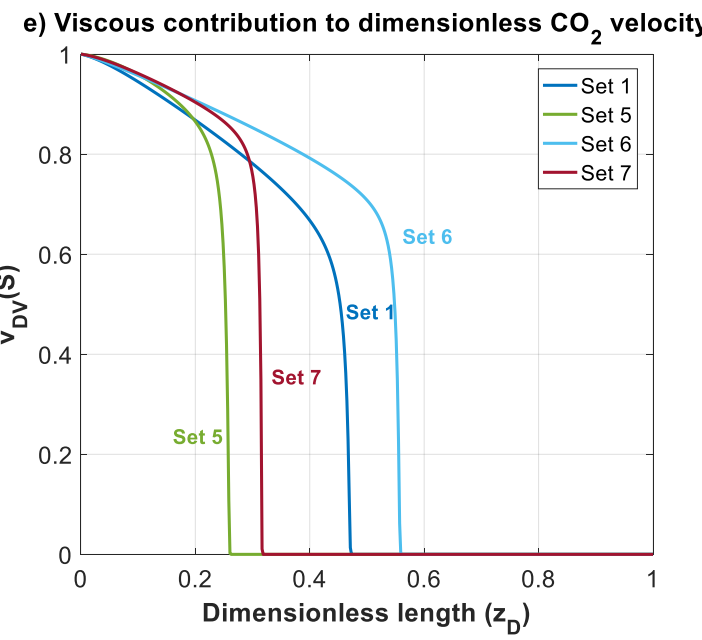

Figure 7. Normalized $\mathrm{CO}_{2}$ saturation and dimensionless $\mathrm{CO}_{2}$ velocity profiles versus dimensionless length at $t_{D}=0.2$ for Datasets 1 and 5-7 (Table 1): (a) normalized saturation; (b) dimensionless $\mathrm{CO}_{2}$ velocity, $\mathbf{v}_{D}$; (c) capillary contribution to $\mathrm{CO}_{2}$ velocity, $\mathbf{v}_{D D} ;(\mathbf{d})$ gravity contribution to $\mathrm{CO}_{2}$ velocity, $\mathbf{v}_{D G} ;$ and (e) viscous contribution to $\mathrm{CO}_{2}$ velocity, $\mathbf{v}_{D V}$.

In Dataset $5, k_{r n w}^{\max }$ is taken to be 0.065 (one order less than $k_{r n w}^{\max }$ in Dataset 1). For a constant total velocity, reducing $\mathrm{CO}_{2}$ endpoint relative permeability by one order of magnitude causes a decrease in $M, N_{C a}$ and $N_{G r}$ by the same order. As shown in Figure 3, this will cause a shift to the lower 
left sector. Reducing $N_{C a}$ and $N_{G r}$ will make the displacement process highly viscous dominant. Additionally, unlike previous datasets, a change in mobility ratio will cause a change in capillary, gravity and viscous functions. As shown in Figure $4 \mathrm{a}, \mathrm{b}$, a decrease in mobility ratio from $M=10$ to $M=1$ will dramatically increase the values of $D(S)$ and $G(S)$ functions. However, since the process is highly viscous dominant (due to small values of $N_{C a}$ and $N_{G r}$ ), the contribution of these forces on plume velocity is negligible. Influence of reducing $M$ on $V(S)$ is shown in Figure 4c (comparing Dataset 5 with Dataset 1). From the frontal advance theory, a higher average saturation of $\mathrm{CO}_{2}$ behind front is obtained for Dataset 5. As expected, the results shown in Figure 7 reveal that a relative permeability curve with low $k_{r n w}^{\max }$ results in less $\mathrm{CO}_{2}$ propagation velocity and a significant delay of the breakthrough time.

In Datasets 6 and 7, the effect of Corey exponents (as a measure of wettability) on behavior of $\mathrm{CO}_{2}$ plume is investigated. Changes in Corey exponents will not change the dimensionless numbers of $N_{C a}$ and $N_{G r}$ and therefore position of various forces in the parameter space shown in Figure 3 will be the same as Dataset 1 . However, the Corey exponents affects shapes of functions $D(S), V(S)$ and $G(S)$. In Dataset 6, nc is kept the same as the one in Dataset $5(n c=2)$, and $n b$ is increased to 4 . As $n b$ increases, the relative permeability to brine, $D(S)$ and $G(S)$ decrease. As shown in Figure 4c, by increasing $n b$, the average saturation behind the front reduces. Therefore, increasing $n b$ will result in a faster plume evolution, and a decrease in time of breakthrough. This effect is better shown by comparing Datasets 6 and 1 in Figure 7. Increasing $n c$, from 2 to 4 in Dataset 7 results in a reduction in relative permeability of $\mathrm{CO}_{2}$. Similar to Dataset 6, values of $D(S)$ and $G(S)$ will decrease, but the average saturation behind the front (Figure $4 \mathrm{c}$ ) increases and therefore a more efficient displacement and a delayed breakthrough time is achieved in this scenario as compared to Dataset 6 .

Since the process is viscous dominant in Datasets 1 and 5-7, contribution of gravity and capillary forces on $\mathrm{CO}_{2}$ plume velocity is negligible, and no countercurrent displacement of brine is observed for these cases. Therefore, in these cases, brine will be displaced along with $\mathrm{CO}_{2}$ to the shallower formation.

Figure $6 \mathrm{~b}$ shows the average normalized saturation versus dimensionless time for Datasets 1 and 5-7. The results showed that a lower endpoint relative permeability of $\mathrm{CO}_{2}$ and therefore lower mobility ratio postpone the breakthrough time. Additionally, increasing $n c$ increases the breakthrough time.

It is important to note that the overall effect of the parameters that appear in both capillary and gravity numbers $\left(N_{C a}\right.$ and $\left.N_{G r}\right)$ as well as capillary, gravity and viscous functions $(D(S), G(S)$, and $V(S)$ ), determine the controlling mechanisms. These parameters (density, viscosity, capillary pressure, relative permeability, etc.) are dependent on the in-situ conditions of temperature, pressure, salinity and the interaction of fluids $\left(\mathrm{CO}_{2}\right.$ and brine) and rock. Therefore, for each case, dimensionless numbers and functions should be evaluated to determine the behavior of the system. To better show the effect of different forces, breakthrough time is calculated for different values of total Darcy velocity for Datasets 1 and 5 where mobility ratios are $M=10$ and $M=1$, respectively. By increasing the total Darcy velocity, $N_{C a}$ and $N_{G r}$ will decrease, reflecting the effect of increasing viscous forces. For instance, for $M=1$, by increasing $\mathbf{v}_{t}$ from $1 \times 10^{-9} \mathrm{~m} / \mathrm{s}$ to $1 \times 10^{-3} \mathrm{~m} / \mathrm{s}$, values of $N_{C a}$ and $N_{G r}$ will both change from as high as 46.5 to 0.00005 . Therefore, for lower values of $\mathbf{v}_{t}$, capillary and gravity forces dominate over viscous forces. Figure 8 a shows effects of gravity forces. Continuous lines display the calculated breakthrough time when all forces are included, and the dashed lines show breakthrough time when gravity effects are neglected. The results demonstrate that gravity effects lead to an earlier breakthrough time for small values of $\mathbf{v}_{t}$ due to increasing buoyancy effects. However, as $\mathbf{v}_{t}$ increases (viscous dominated regime), the effect of gravity becomes negligible. Next, we study the effect of capillary forces on breakthrough time. As shown in Figure 8b, capillary forces have a significant effect on breakthrough time for small values of $\mathbf{v}_{t}$. In other words, neglecting capillary effects results in overestimation of breakthrough time. However, the influence of capillary forces becomes negligible by increasing $\mathbf{v}_{t}$. 

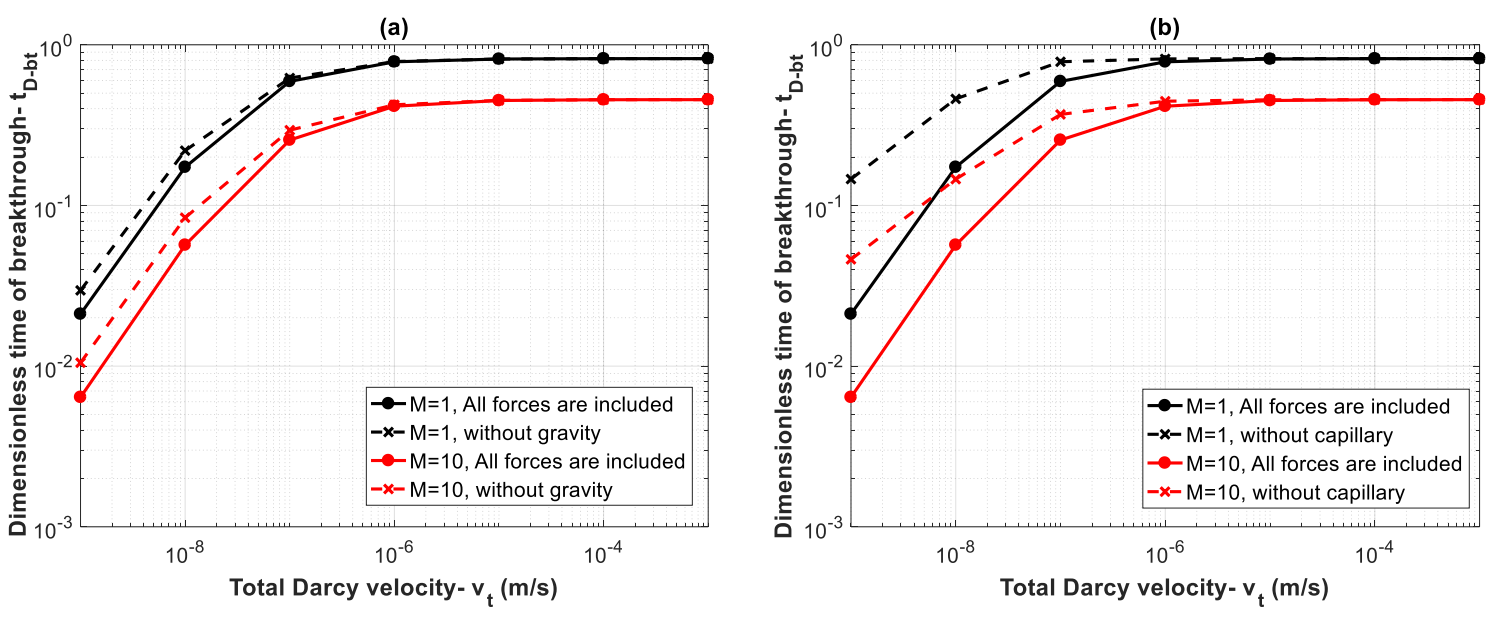

Figure 8. Influence of (a) gravity forces and (b) capillary forces on breakthrough time with varying velocity from $1 \times 10^{-9} \mathrm{~m} / \mathrm{s}$ to $1 \times 10^{-3} \mathrm{~m} / \mathrm{s}$ for two mobility ratios of $M=1$ (Dataset 5) and $M=10$ (Dataset 1).

\subsection{Case Study on $\mathrm{CO}_{2}$ Storage Aquifers in Western Canada}

In this section, the developed model is used to study potential $\mathrm{CO}_{2}$ storage sites in central Alberta, Canada. Province of Alberta has the largest greenhouse gas emissions in Canada, with annual emissions close to $274.1 \mathrm{Mt} \mathrm{CO}_{2}$ in 2015 [34]. The province is underlain by the Alberta basin, which is suitable for $\mathrm{CO}_{2}$ geological sequestration in all parts except for its shallow northeastern corner [35]. The largest concentration of $\mathrm{CO}_{2}$ sources in Alberta is in the Edmonton region where four coal-fired power plants are located near Wabamun Lake, west of Edmonton, which have combined annual $\mathrm{CO}_{2}$ emissions of more than $30 \mathrm{Mt} \mathrm{CO}_{2}$ [36]. Figure 9 shows the location of major $\mathrm{CO}_{2}$ emission sources in central Alberta, Canada. $\mathrm{CO}_{2}$ sequestration in deep saline aquifers in proximity of these power plants is a promising option for reducing $\mathrm{CO}_{2}$ atmospheric emissions since the deep coal seams and oil and gas reservoirs in local area do not have sufficient capacity for sequestration of $\mathrm{CO}_{2}$. Because $\mathrm{CO}_{2}$ sequestration in geological media and especially in deep saline aquifers is a recently growing field, no relevant measured data have been published regarding displacement characteristics of $\mathrm{CO}_{2}$-brine systems at in situ conditions until early 2000. Relevant data were only available for $\mathrm{CO}_{2}$-oil systems for enhanced oil recovery purposes and a handful of measurements for $\mathrm{CO}_{2}$-oil-brine ternary systems.

To fill the knowledge gap, Bennion and Bachu conducted a series of experiments to measure relative permeability and capillary pressure characteristics at in-situ conditions for $\mathrm{CO}_{2}$-brine systems [33,37-42]. They studied sandstone, carbonate, shale and anhydrite rock formations in the Alberta basin in central Alberta. These formations are general representatives of the in-situ temperature, pressure, and salinity in entire Alberta basin, and likely for all on-shore North American sedimentary basins.

Table 2 presents a summary of in-situ conditions for the cored intervals from three sandstone and three carbonate formations in the Wabamun Lake area, southwest of Edmonton, Alberta [33,37]. The location of the wells from which core samples were taken is shown in Figure 9. For the Wabamun Group, two samples with low and high permeability were evaluated which results in a total of seven different rock sets. Temperatures in Table 2 are evaluated based on the depth of the samples by considering a geothermal gradient of $25^{\circ} \mathrm{C} / \mathrm{km}$ [37].

The stratigraphic downhole model for strata in the Wabamun Lake area is available in the literature [37]. Since site specific data for leakage pathways are not available, we used the same data reported for the storage formations to represent the characteristics of the leakage pathway. Nevertheless, the analysis provided is general and allows application of the developed scaling to a leakage pathway when site specific data are available. 


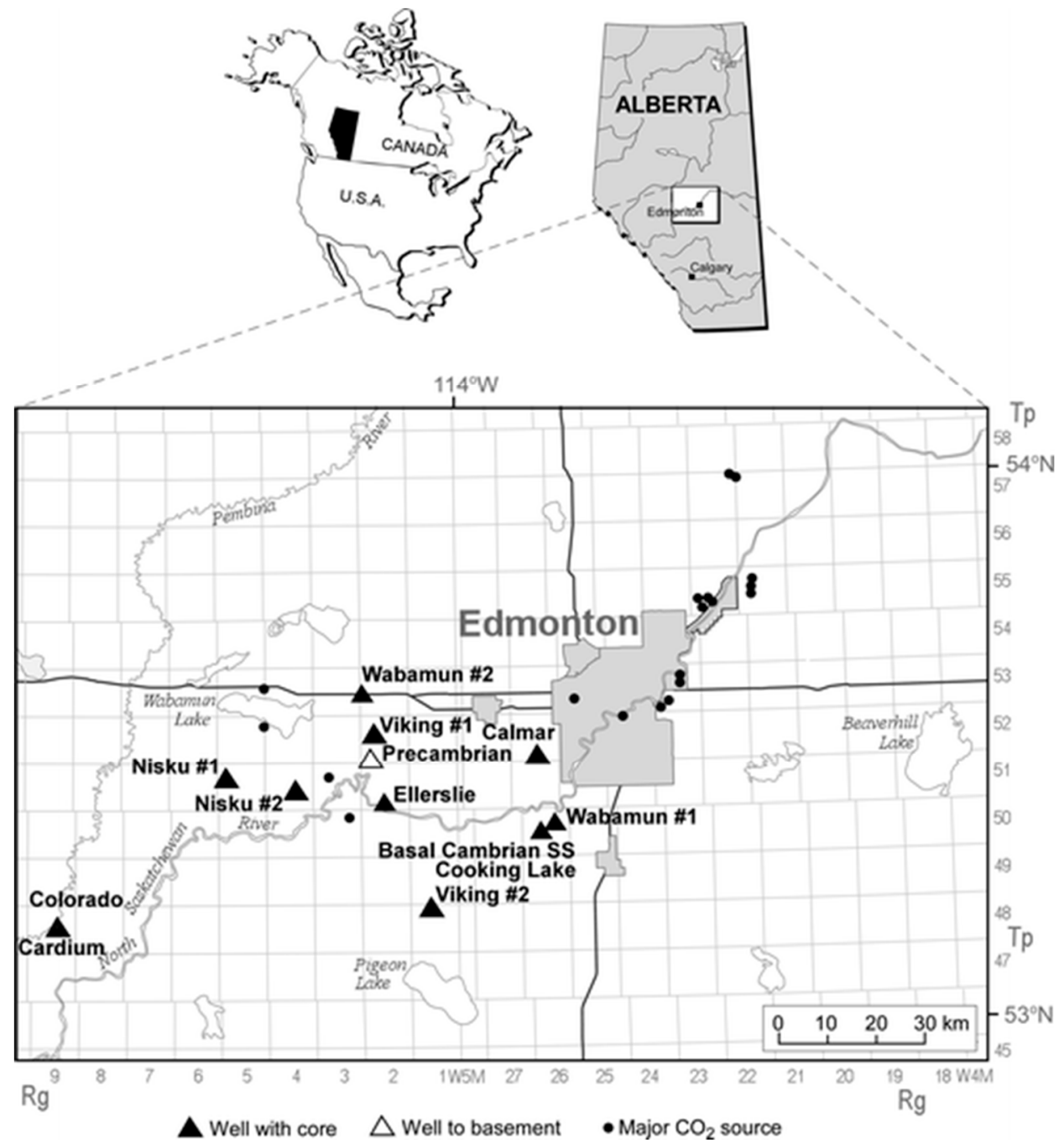

Figure 9. Location of large stationary $\mathrm{CO}_{2}$ sources in central Alberta, Canada and wells with core samples used in experiments [33].

Table 2. In-situ conditions for rock samples from Wabamun Lake area, Alberta basin, Canada [33].

\begin{tabular}{cccccccc}
\hline ID * & Unit & Lithology & Depth $(\mathbf{m})$ & $\begin{array}{c}\text { Porosity } \\
(\text { Fraction) }\end{array}$ & $\begin{array}{c}\text { Pressure } \\
(\mathbf{M P a})\end{array}$ & $\begin{array}{c}\text { Temp. } \\
\left({ }^{\circ} \mathbf{C}\right)\end{array}$ & $\begin{array}{c}\text { Salinity } \\
(\mathbf{m g} / \text { Liters })\end{array}$ \\
\hline B & Basal Cambrian & Sandstone & 2734 & 0.117 & 27 & 75 & 248,000 \\
E & Ellerslie & Sandstone & 1463 & 0.126 & 10.9 & 40 & 97,217 \\
V & Viking\#1 & Sandstone & 1240 & 0.125 & 8.6 & 35 & 28,286 \\
C & Cooking lake & Carbonate & 1889 & 0.099 & 15.4 & 55 & 233,417 \\
N & Nisku\#1 & Carbonate & 2050 & 0.097 & 17.4 & 56 & 136,817 \\
WL & Wabamun \#1 (Low Perm) & Carbonate & 1353 & 0.079 & 11.9 & 41 & 144,304 \\
WH & Wabamun \#2 (High Perm) & Carbonate & 1603 & 0.148 & 11.9 & 41 & 144,304 \\
\hline
\end{tabular}

* For easy identification in the figures, letters have been assigned to different sample units.

Other parameters used in this study are presented in Table 3. All the parameters in Table 3, except the ones with asterisk, are taken from measurements of Bennion and Bachu $[37,40]$. Bennion and Bachu [37] measured relative permeability parameters at reservoir conditions for rock samples of Table 2 and reported absolute permeability, $\mathrm{CO}_{2}$ and brine viscosity, end-point relative permeability of $\mathrm{CO}_{2}\left(k_{r n w}^{\max }\right)$, residual brine saturation $\left(S_{w r}\right)$, and generated drainage relative permeability curves for $\mathrm{CO}_{2}$-brine systems. In another paper, Bennion and Bachu [40] reported the fitted Corey exponents based on their measured relative permeability data for rock samples of Table 2. Corey exponents are 
listed in Table 3. In another work, Bennion and Bachu [38] reported capillary pressure, interfacial tension and pore size distribution characteristics on a series of carbonate and sandstone formations from Wabamun Lake area in Alberta, together with those formations given in Table 2. We used the reported $\mathrm{CO}_{2}$-brine capillary pressure curves, from their study, and curve-fitted to Equation (15). The evaluated capillary entry pressures $\left(p_{d}\right)$ are reported in Table 3.

In Table 3, density of brine is calculated based on Rowe and Chou [43] correlation using temperature, pressure and salt mass fraction for different formations. $\mathrm{CO}_{2}$ density is calculated using Soave-Redlich-Kwong (SRK) equations of state [44]. Total Darcy velocity $\left(\mathbf{v}_{t}\right)$ in Table 3 is estimated based on $\mathbf{v}_{t}=k \Delta \rho g / \mu_{n w}$, which reflects the maximum buoyancy velocity for $\mathrm{CO}_{2}$ and is calculated using Darcy's law based on the parameters for each formation. The calculated values in Table 3 are in the range of reported Darcy velocities for $\mathrm{CO}_{2}$ in the literature [45,46]. In addition, although different velocities could happen in the reservoir, this can be a good measure for comparison of different formations. Finally, we considered a length of $500 \mathrm{~m}$ and a tilt angle of $\pi / 2$ in this study. Generally, there are no data on the geometry and direction of the leakage pathways for the formations. We considered identical length and tilt angles for the study of all formations to provide a fair comparison between different storage formations.

Table 3. Simulation parameters and calculated values of $M, N_{C a}$ and $N_{G r}$ for rock samples of Table 2.

\begin{tabular}{|c|c|c|c|c|c|c|c|}
\hline Data & $\begin{array}{l}\text { Basal } \\
\text { Camb. }\end{array}$ & Ellerslie & Viking & $\begin{array}{l}\text { Cooking } \\
\text { Lake }\end{array}$ & Nisku & $\begin{array}{c}\text { Wab. Low } \\
\text { Perm }\end{array}$ & $\begin{array}{l}\text { Wab. High } \\
\text { Perm }\end{array}$ \\
\hline Length of domain, $L^{*}(\mathrm{~m})$ & 500 & 500 & 500 & 500 & 500 & 500 & 500 \\
\hline Brine Viscosity, $\mu_{w}(\mathrm{mPa} \cdot \mathrm{s})$ & 0.733 & 0.784 & 0.755 & 0.864 & 0.661 & 0.863 & 0.863 \\
\hline End-point rel-perm of $\mathrm{CO}_{2}, k_{r n w}^{\max }$ & 0.5446 & 0.1156 & 0.3319 & 0.0685 & 0.1768 & 0.5289 & 0.1883 \\
\hline Absolute permeability, $k(\mathrm{mD})$ & 0.081 & 0.376 & 2.7 & 65.3 & 45.9 & 0.018 & 67 \\
\hline Residual Brine Saturation, $S_{w r}$ & 0.294 & 0.659 & 0.558 & 0.476 & 0.33 & 0.595 & 0.569 \\
\hline Capillary entry pressure, $p_{d}^{*}(\mathrm{MPa})$ & 0.226 & 3.382 & 0.121 & 0.014 & 5.794 & 0.341 & 0.087 \\
\hline $\mathrm{CO}_{2}$ Density, $\rho_{n w}^{*}\left(\mathrm{~kg} / \mathrm{m}^{3}\right)$ & 723.8 & 658.1 & 626.7 & 645.4 & 683.3 & 678.9 & 678.9 \\
\hline Brine Density, $\rho_{w}^{*}\left(\mathrm{~kg} / \mathrm{m}^{3}\right)$ & 1140.5 & 1060.9 & 1016.9 & 1138.9 & 1080.4 & 1090.5 & 1090.5 \\
\hline Tilt angle, $\theta^{*}$ & $\pi / 2$ & $\pi / 2$ & $\pi / 2$ & $\pi / 2$ & $\pi / 2$ & $\pi / 2$ & $\pi / 2$ \\
\hline Total Buoyancy velocity, $\mathrm{v}_{t}^{*}(\mathrm{~m} / \mathrm{s})$ & $5.34 \times 10^{-9}$ & $2.75 \times 10^{-8}$ & $1.91 \times 10^{-7}$ & $5.65 \times 10^{-6}$ & $3.19 \times 10^{-6}$ & $1.3 \times 10^{-9}$ & $4.83 \times 10^{-6}$ \\
\hline$M$ & 6.44 & 1.68 & 4.64 & 1.06 & 2.09 & 8.15 & 2.90 \\
\hline
\end{tabular}

* Estimated values (details are available in the text).

The calculated values for $M, N_{C a}$ and $N_{G r}$ are presented in the last three rows of Table 3 . The estimated values of mobility ratio have a wide range, starting at 1.06 for Cooking Lake formation to 8.15 for Wabamun Low Perm formation. Estimated values of $N_{C a}$ and $N_{G r}$ are shown in a $N_{G r}-N_{C a}$ space in Figure 10. A reference equilibrium state between gravitational and viscous forces is indicated with dotted line at $N_{G r}=1$, and between capillary and viscous forces at $N_{C a}=1$. As shown in Figure 10, all rock samples fall into the lower left sector where viscous forces dominate over capillary and gravity forces. It is seen that $N_{C a}$ varies three orders of magnitude, while variations of $N_{G r}$ are more gradual and fall within one order of magnitude for different formations.

As shown in Figure 10, Cooking Lake carbonate has the lowest capillary and gravity numbers of $N_{C a}=0.0004$ and $N_{G r}=0.0687$. The highest effect of gravity forces is in Basal Cambrian sandstone with $N_{G r}=0.5444$, and the highest effect of capillary forces is in Nisku carbonate with $N_{C a}=0.5260$.

It is worth mentioning that we used maximum buoyance velocity in the previous calculations. However, velocity of a migrating $\mathrm{CO}_{2}$ plume may vary within orders of magnitude. To study the effect of total velocity used in our scaling analysis, we perform an analysis to investigate the effect of velocity on the position of various storage formations in the $N_{G r}-N_{C a}$ parameter map. Using different values for the total Darcy velocity leads to different capillary and gravity numbers, but the ratio of these forces remains the same. Figure 11 shows the estimated values for $N_{C a}$ and $N_{G r}$ when total Darcy velocity is varied from $10^{-10} \mathrm{~m} / \mathrm{s}$ to $10^{-4} \mathrm{~m} / \mathrm{s}$ for all the formations shown in Table 3 . This figure indicates 
that the ratio of capillary to gravity numbers stays the same as the velocity is changing while various formations have different ratios. In the case of Cooking Lake formation, for instance, while gravity forces are at equilibrium with viscous forces (i.e., $N_{G r}=1$ ), capillary forces are greatly dominated by viscous forces $\left(N_{C a}=0.006\right)$. On the other hand, for Nisku formation, when $N_{G r}=1$, capillary number is $N_{C a}=3.33$, which shows the effects of capillary forces are much higher for Nisku formation than that for Cooking Lake formation.

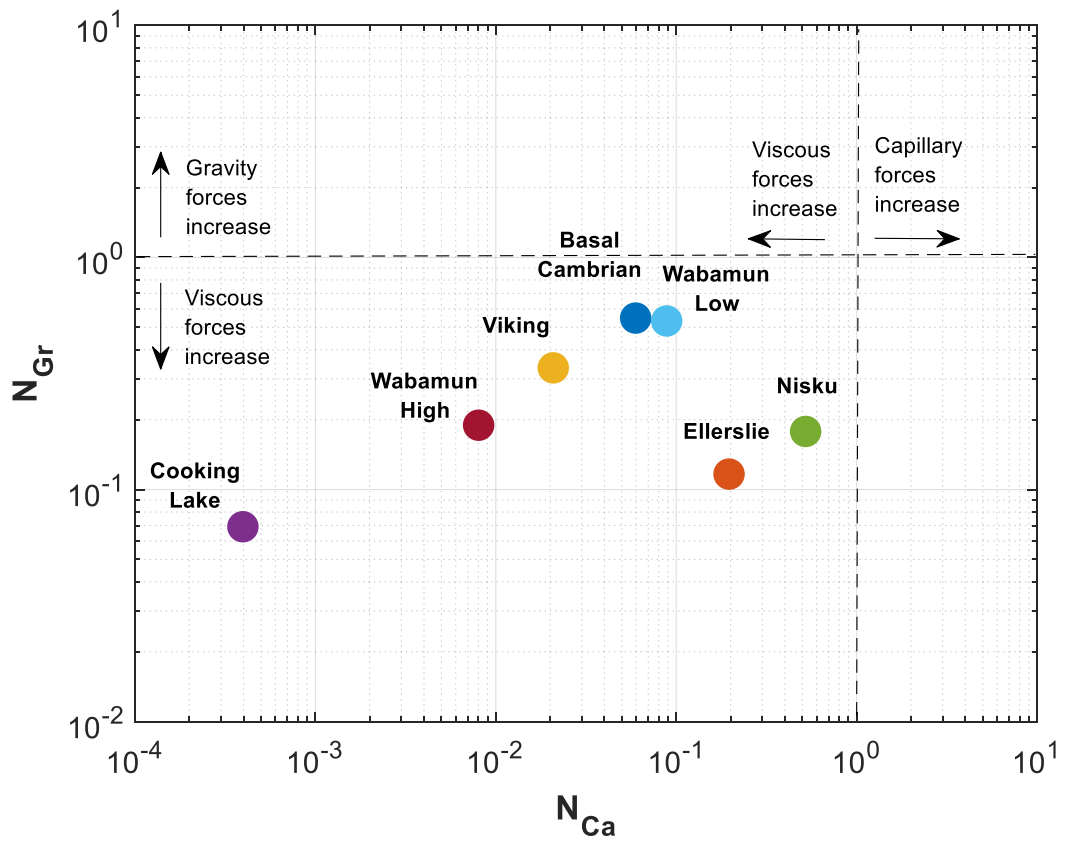

Figure 10. Gravity number $\left(N_{G r}\right)$ versus capillary number $\left(N_{C a}\right)$ for different formations in Table 3.

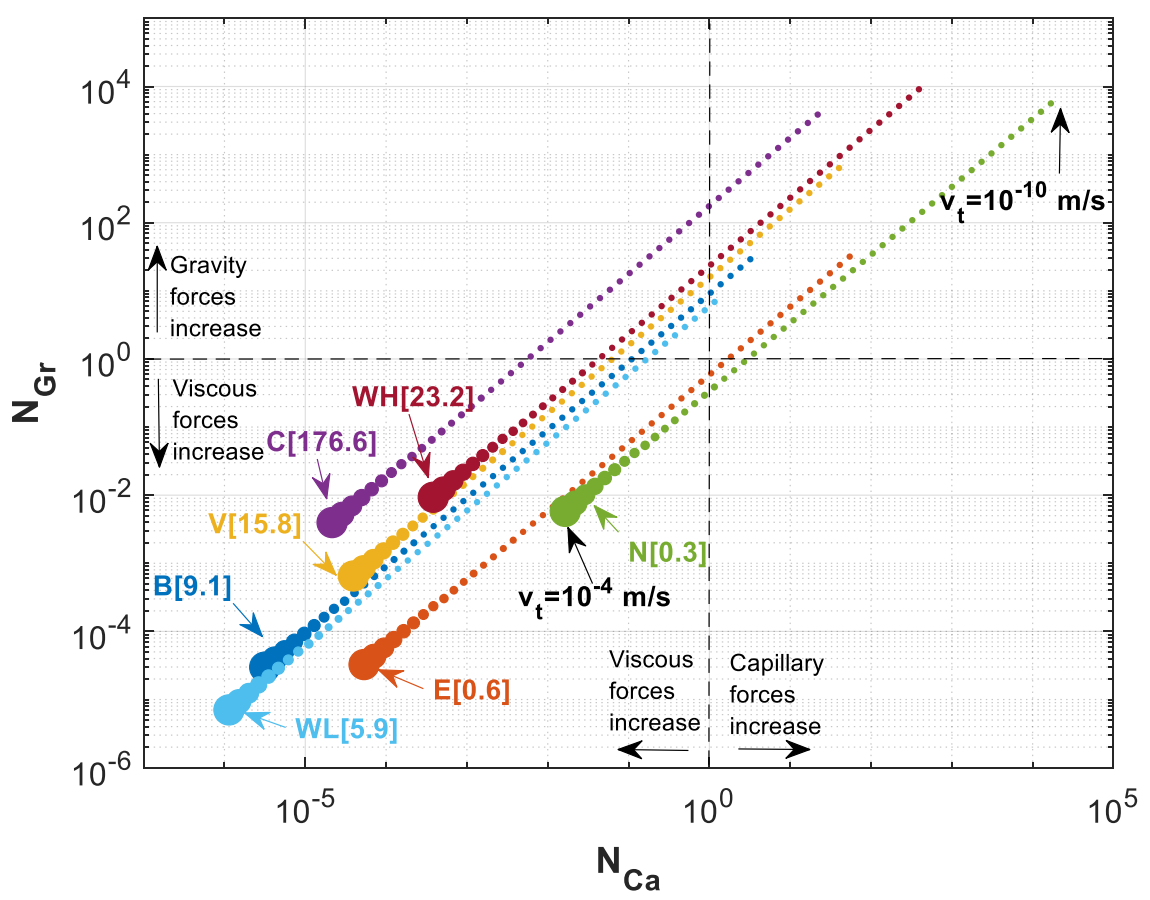

Figure 11. $N_{G r}$ versus $N_{C a}$ for a varying total Darcy velocity $\left(\mathbf{v}_{t}\right)$ ranging from $10^{-10} \mathrm{~m} / \mathrm{s}$ to $10^{-4} \mathrm{~m} / \mathrm{s}$ for different formations of Table 3. The numbers in brackets is the ratio of $N_{G r} / N_{C a}$ for different formations. 
Other than $N_{C a}$ and $N_{G r}$, relative permeability parameters are important in estimations of rate of leakage. Figure 12a-c shows capillary, gravity and viscous functions for all formations shown in Table 3. For all of the rock samples except Nisku and Ellerslie formations, the effect of capillary and gravity forces is reduced due to the small values of $N_{C a}$ and $N_{G r}$, and therefore, viscous function, $V(S)$, is the dominant term for estimating saturation and velocity profiles. Mobility ratio as well as Corey exponents of $n c$ and $n b$ determine the behavior of capillary, gravity and viscous functions. As indicated in previous section, a lower mobility ratio and a higher Corey exponent for $\mathrm{CO}_{2}$ increase the time of breakthrough and the average normalized saturation behind the displacement front. Among the rock samples, Cooking Lake formation has the lowest mobility ratio of $M=1.06$ and highest Corey exponent for $\mathrm{CO}_{2}(n c=5.6)$, which results in the highest average saturation behind the displacement front (Figure 12c). In addition, because of small mobility ratio, the values of $D(S)$ and $G(S)$ are relatively high for this case, though their effect on velocity profile is insignificant. Despite similar Corey exponents ( $n c$ and $n b$ ) of Wabamun Low Perm and Cooking Lake formation, mobility ratio is higher and equal to $M=8.15$ for Wabamun Low Perm. Further, by comparing these formations (Figure 12a,b), it can be inferred that Wabamun Low Perm has smaller $D(S)$ and $G(S)$ values in comparison to Cooking Lake formation, and the average saturation behind the displacement front is lower for Wabamun Low Perm as well (see Figure 12c). For Basal Cambrian sandstone, mobility ratio is relatively high $(M=6.44)$, however, the average saturation behind the displacement front is also high, since Corey exponent for $\mathrm{CO}_{2}$ is $n c=5$ (Figure 12c). Therefore, contribution of $D(S)$ and $G(S)$ are negligible due to the value of mobility ratio (Figure 12a,b). Nisku formation has the lowest Corey exponent for $\mathrm{CO}_{2}, n c=1.1$, and even though the mobility ratio for this formation is relatively small and equal to $M=2.09$, it has the lowest average saturation behind the displacement front (Figure 12c). Additionally, as shown in Figure 12a,b, contribution of $D(S)$ and $G(S)$ are relatively high for this dataset. Finally, the behavior of capillary, gravity and viscous functions for Wabamun High Perm and Ellerslie formations are very similar, since their mobility ratios and Corey exponents are almost equal.

Figure 13 shows the normalized gas saturation and contribution of different forces on $\mathrm{CO}_{2}$ dimensionless velocity, for all rock samples at time $t_{D}=0.2$. It can be immediately observed that, due to the domination of viscous forces over capillary and gravity forces (small values of $N_{C a}$ and $N_{G r}$ ), plume evolution and the dimensionless velocity greatly resemble the viscous function $V(S)$, for all formations, except Nisku and Ellerslie, for which capillary forces are relatively high. Nisku formation has the fastest plume evolution and a countercurrent flow of brine is observed at the inlet due to the effect of capillary forces (Figure 13b,c). Same as Nisku formation, Ellerslie formation does not develop a sharp font, and contribution of capillary forces on velocity causes a small countercurrent flow of brine at the inlet.

$\mathrm{CO}_{2}$ front is relatively sharp for the rest of the formations. The front propagation for Cooking Lake formation is slow compared to other formations, which is due to the small mobility ratio and high $n c$, as well as small $N_{C a}$ and $N_{G r}$. Shapes of the $\mathrm{CO}_{2}$ plume and velocity profiles are similar for Basal Cambrian and Wabamun Low Perm formations. This is because of their position on $N_{G r}-N_{C a}$ map (Figure 10) and similar values of mobility ratio and $n c$ (Table 3). Again, in the above analysis, we used maximum buoyance velocity. However, velocity of a migrating $\mathrm{CO}_{2}$ plume may vary within orders of magnitude, which can change the position of the formations in the $N_{G r}-N_{C a}$ parameter map. Nevertheless, the scaling analysis provided is general and allows application to specific storage site when site specific data are available.

The average normalized gas saturation versus dimensionless time for all the formations are shown in Figure 14, which are in good agreement with the saturation and velocity profiles discussed earlier. For instance, for the Cooking Lake formation, the breakthrough of $\mathrm{CO}_{2}$ is delayed due to the less diffusive nature of the displacement front, whereas in the Nisku formation, the effect of capillary forces leads to a diffusive shape front and therefore an earlier breakthrough is expected with lower $\mathrm{CO}_{2}$ saturation. 
(a)

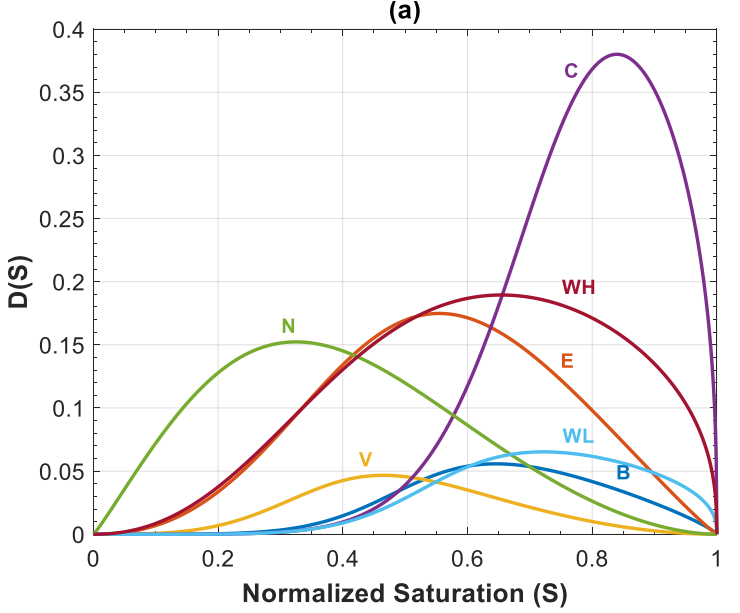

(b)

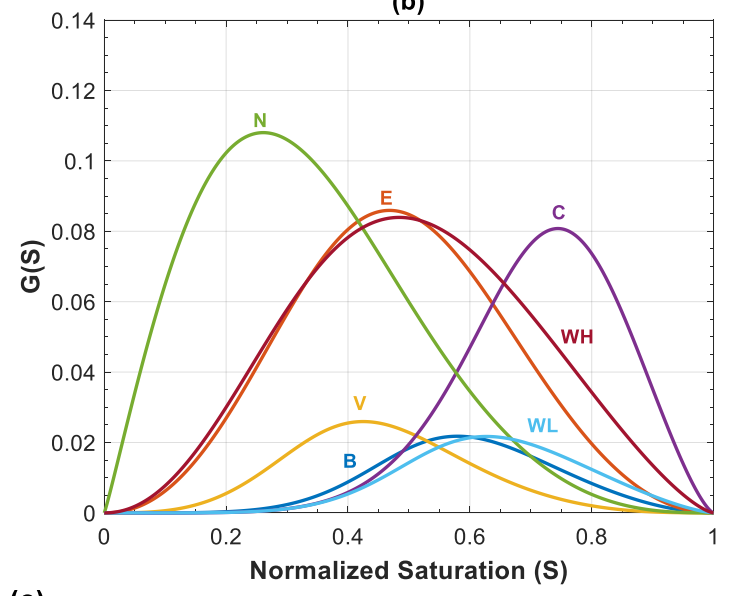

(c)

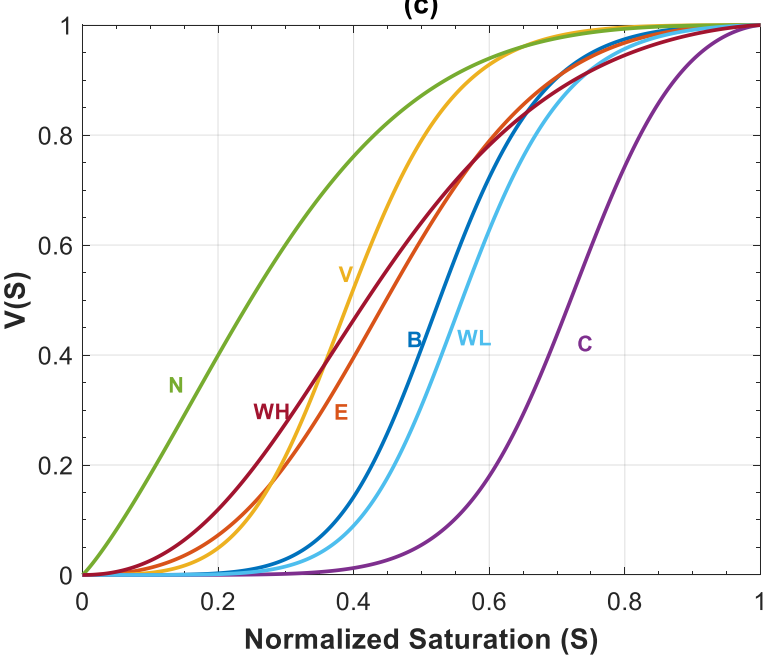

Figure 12. (a) Capillary function $D(S)$; (b) gravity function $G(S)$; and (c) viscous function, $V(S)$, for different rock samples of Table 2.

Since the discussed values are dimensionless, further discussion on the real time of breakthrough and the cumulative amount of leaked $\mathrm{CO}_{2}$ requires site specific data such as residual brine saturation and porosity of the formations. These parameters are not identical for all the formations and taking these parameters into account would influence the interpretation of results, as described in the following.

The real time of breakthrough and cumulative amount of leakage are calculated based on the dimensionless time of breakthrough and the average normalized saturation in Figure 14 and Table 4. The dimensionless time of breakthrough is converted to the real time of breakthrough using Equations (9) and (10), and the cumulative amount of leakage per $\mathrm{m}^{2}$ of the cross-sectional area of the migration pathway is calculated using $\bar{S} \times\left(1-S_{w r}\right) \times L \times \phi$, where $S_{w r}$ is the brine residual saturation and $\bar{S}$ is the average normalized saturation, $\bar{S}=\int_{0}^{1} S d z_{D}$. The cumulative amount of leakage is plotted versus time for all formations in Figure 15. As expected, the results are different from what has been expected based on Figure 14. This is essentially due to the different values of residual brine saturation and porosity of different formations. 

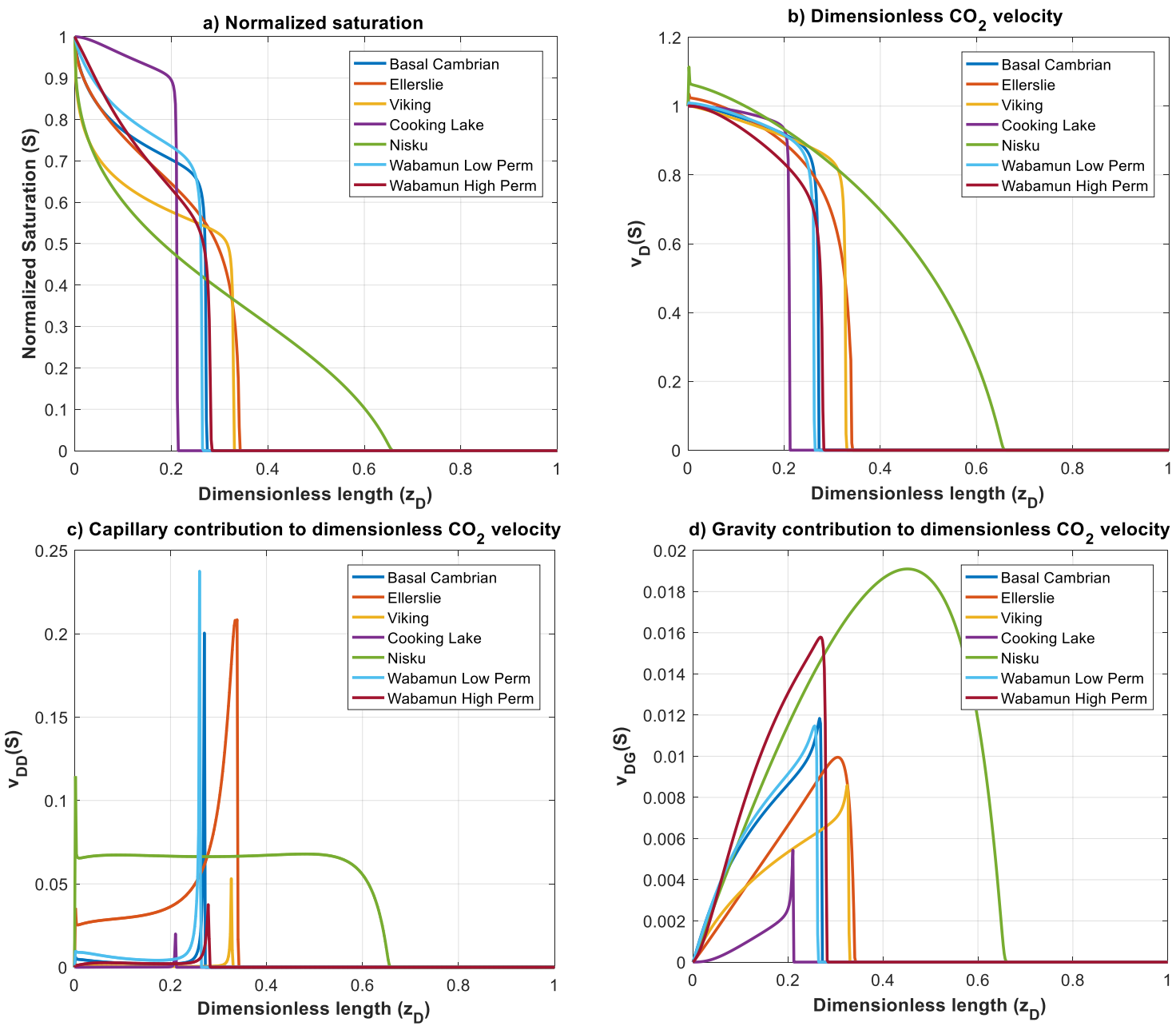

e) Viscous contribution to dimensionless $\mathrm{CO}_{2}$ velocity

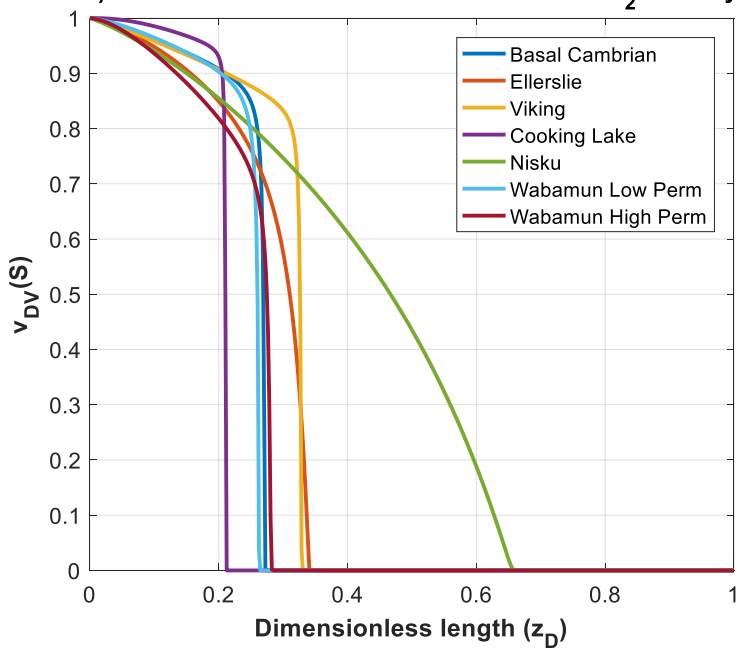

Figure 13. Normalized $\mathrm{CO}_{2}$ saturation and dimensionless $\mathrm{CO}_{2}$ velocity profiles versus dimensionless length at $t_{D}=0.2$ for rock samples in Table 3: (a) normalized saturation; (b) dimensionless $\mathrm{CO}_{2}$ velocity, $\mathbf{v}_{D}$; (c) capillary contribution to $\mathrm{CO}_{2}$ velocity, $\mathbf{v}_{D D}$; (d) gravity contribution to $\mathrm{CO}_{2}$ velocity, $\mathbf{v}_{D G}$; and (e) viscous contribution to $\mathrm{CO}_{2}$ velocity, $\mathbf{v}_{D V}$. 


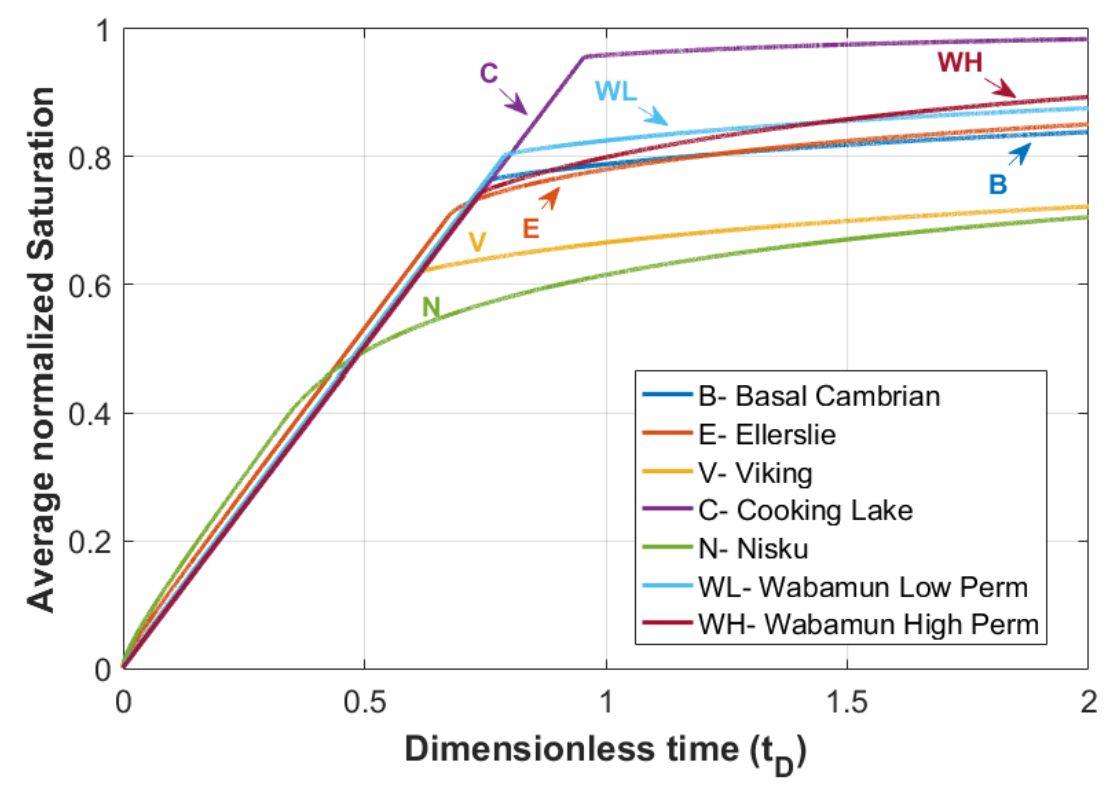

Figure 14. Average normalized saturation versus dimensionless time $\left(t_{D}\right)$ for rock samples in Table 2.

Table 4. Time of breakthrough and cumulative leakage calculated for different formations of Table 3.

\begin{tabular}{|c|c|c|c|c|c|}
\hline Formation & $\begin{array}{c}\text { Dimensionless } \\
\text { Time of } \\
\text { Breakthrough, } \\
t_{D-b t}\end{array}$ & $\begin{array}{c}\text { Total } \\
\text { Buoyancy } \\
\text { Velocity, } v_{t} \\
(\mathrm{~m} / \mathrm{s})\end{array}$ & $\begin{array}{c}\text { Real time of } \\
\text { Breakthrough, } \\
t \text { (Years) }\end{array}$ & $\begin{array}{c}\text { Average } \\
\text { Normalized } \\
\text { Saturation, } S\end{array}$ & $\begin{array}{l}\text { Cumulative } \\
\text { Leakage at Time of } \\
\text { Breakthrough, } \\
\left(\mathrm{m}^{3} / \mathrm{m}^{2}\right)\end{array}$ \\
\hline Basal Cambrian & 0.7544 & $5.34 \times 10^{-9}$ & 185.0 & 0.7611 & 31.4 \\
\hline Ellerslie & 0.6747 & $2.75 \times 10^{-8}$ & 16.7 & 0.7070 & 15.2 \\
\hline Viking & 0.6161 & $1.91 \times 10^{-7}$ & 2.8 & 0.6184 & 17.1 \\
\hline Nisku & 0.3396 & $3.19 \times 10^{-6}$ & 0.11 & 0.3949 & 12.83 \\
\hline Wab. Low Perm & 0.7893 & $1.3 \times 10^{-9}$ & 308.5 & 0.8007 & 12.81 \\
\hline Wab. High Perm & 0.7355 & $4.83 \times 10^{-6}$ & 0.15 & 0.7390 & 23.6 \\
\hline
\end{tabular}

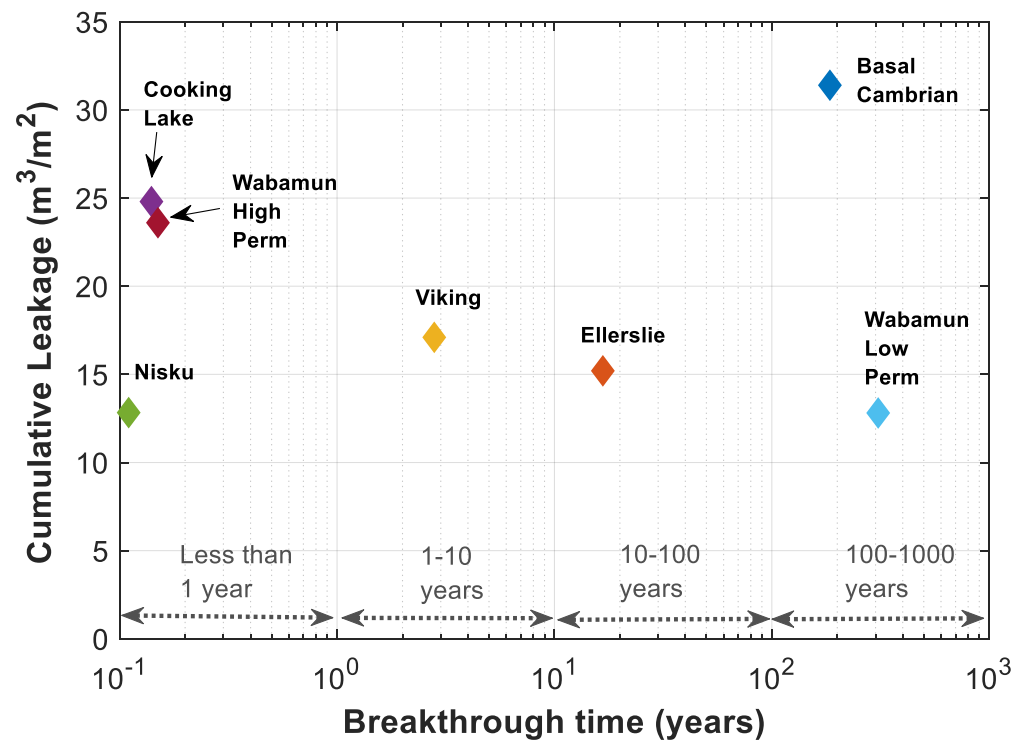

Figure 15. Cumulative leakage per $\mathrm{m}^{2}$ of leakage pathway versus time for rock samples of Table 3.

The maximum Darcy buoyancy velocity considered for each formation has a great impact on estimating the breakthrough time. Cooking Lake, Wabamun High Perm, and Nisku formations have the 
highest Darcy buoyancy velocities and thus lower estimated breakthrough times of 51, 56, and 40 days, respectively. Darcy buoyancy velocity decreases for Viking, Ellerslie, Basal Cambrian and Wabamun Low Perm formations, respectively, and as can be seen in Figure 15, time of breakthrough is delayed for these formations, correspondingly. Porosity times maximum saturation, $\phi^{*}=\left(1-S_{w r}\right) \times \phi$, gives an estimate of the available pore volume for $\mathrm{CO}_{2}$.

In addition, time of breakthrough is highest for Wabamun Low Perm formation, ( $\sim 308$ years), since the estimated Darcy velocity is lowest for this case compared to the other formations, $\left(\mathbf{v}_{t}=1.3 \times 10^{-9}\right)$, and at the same time, the amount of leaked $\mathrm{CO}_{2}$ is lowest for this case, due to the small pore volume available for fluids flow $\left(\phi^{*}=0.03\right)$. A possible leakage from a storage aquifer through a leakage pathway can be remediated specially if detected early enough. On the other hand, chances of contribution of other trapping mechanisms and therefore reducing the amount of leakage is higher for cases with higher time of leakage, such as Wabamun Low Perm or Basal Cambrian formations.

Celia et al. [47] assessed risk of brine and $\mathrm{CO}_{2}$ leakage through abandoned wells in the same area that we discussed here (as depicted in Figure 9). They simulated 50 years of $\mathrm{CO}_{2}$ injection using a semi-analytical modeling approach over a study area of $2500 \mathrm{~km}^{2}$. They concluded that the behavior of the system is dependent on the interplay of formation and fluid properties, maximum injectivity of the formation and the properties of the leaky wells. Generally, lower number of oil and gas wells penetrate the caprocks of deeper formations and this will clearly result in a tradeoff between depth of injection and risk of leakage. However, their simulations imply that the number and design of the injection wells and injectivity of the formations play a critical role on the assessment of leakage. Due to lack of data, they assigned the well permeabilities based on the probability distribution. With their assumption of a single vertical injection well and considering the limitation of injectivity, they concluded that Nisku and the Basal Cambrian formations are the two viable options for $\mathrm{CO}_{2}$ injection.

\section{Conclusions}

In this study, a numerical model is developed to investigate the influence of driving forces on $\mathrm{CO}_{2}$ plume evolution and breakthrough time during a leakage from a water saturated pathway. The results of this study can be used for estimation of leakage for different potential $\mathrm{CO}_{2}$ storage sites where formation properties of leakage pathways are available.

Dimensionless terms of $D(S), G(S)$ and $V(S)$ along with dimensionless capillary and gravity numbers are introduced to express the effect and ratio of capillary, gravity and viscous forces. A leakage process is characterized by a two-phase system, in which the non-wetting and less viscous $\mathrm{CO}_{2}$ displaces the resident brine. Results from this study show that increasing the effect of gravity forces (and therefore $N_{G r}$ ) leads to an earlier breakthrough of $\mathrm{CO}_{2}$. Similar to $N_{G r}$, by increasing the effect of capillary forces $\left(N_{C a}\right)$ a diffusive-like front is established, which also results in an earlier breakthrough. At high values of $N_{C a}$, a backward flow of brine is observed as $\mathrm{CO}_{2}$ migrates upward. For high $N_{C a}$, the saturation distribution is diffusive in nature, which results in a gradually leaking $\mathrm{CO}_{2}$. In terms of operations, a sharp front leakage may be more problematic than a gradual leakage (diffusive dominated flow) since it is more difficult to take remedial actions to prevent leakage in case of a sudden release of $\mathrm{CO}_{2}$. Additionally, it is seen that the effect of increasing $N_{G r}$ by one order of magnitude on accelerating the breakthrough time, is much less than that of increasing $N_{C a}$.

The relative permeability-saturation relationships have shown to be of great influence for plume evolution. Results show that a low relative permeability of $\mathrm{CO}_{2}$ (low end-point relative permeability of $\mathrm{CO}_{2}$ or high Corey exponent for $\mathrm{CO}_{2}$ ) results in a more compact plume evolution. A compact front propagation results in a delayed breakthrough but has the risk of a sudden release of a large volume of leaked $\mathrm{CO}_{2}$.

The developed numerical model was applied to different potential storage formations in Western Canada. In the absence of site specific data for leakage pathways, data reported for the corresponding storage formations were used. Nevertheless, the presented analysis provided is general and allows application of the developed scaling to specific leakage pathway when data are available. For these 
formations, it is seen that $N_{C a}$ varies within three orders of magnitude, while variations of $N_{G r}$ are more gradual and fall within one order of magnitude. In addition, due to small values of $N_{C a}$ and $N_{G r}$, plume evolution and the dimensionless velocity greatly resemble the viscous function, $V(S)$, for all formations, except Nisku and Ellerslie, for which capillary forces are relatively high. It is worth mentioning that, for scaling analysis, we used the maximum buoyancy velocity for different formations, however the velocity of a migrating $\mathrm{CO}_{2}$ plume may vary within orders of magnitude which may change the position of various storage formations in the $N_{G r}-N_{C a}$ parameter map. Comparing different formations in Alberta basin revealed that in determining time of breakthrough and the cumulative amount of leaked $\mathrm{CO}_{2}$, parameters such as residual brine saturation and porosity of the medium are critical and significantly contribute to the interpretation of results.

The numerical models presented in this paper predict displacement process for a one-dimensional homogenous media. However, the processes induced by $\mathrm{CO}_{2}$ leakage may be quite complex and may operate on a broad range of space and timescales. For instance, viscous fingering may significantly alter the shape of $\mathrm{CO}_{2}$-water displacement front, creates channels with high $\mathrm{CO}_{2}$ effective permeability and thus earlier leakage of $\mathrm{CO}_{2}$. In addition, the leaked $\mathrm{CO}_{2}$ may undergo phase changes due to temperature variations, which have not been considered in this study. Therefore, further research should consider temperature variation as well as two- and three-dimensional models with detailed representation of leakage pathways heterogeneities for a more realistic representation of the problem.

Author Contributions: Conceptualization, P.H., and H.H.; Methodology, P.H., and H.H.; Validation, P.H., and H.H.; Formal Analysis, P.H., and H.H.; Investigation, P.H., and H.H.; Data Curation, P.H.; Writing-Original Draft Preparation, P.H.; Writing-Review \& Editing, P.H., and H.H.; Supervision, H.H.; Project Administration, H.H.; Funding Acquisition, H.H.

Funding: This work was supported by a Discovery Grant from the Natural Sciences and Engineering Research Council of Canada (NSERC).

Acknowledgments: The authors would like to thank four reviewers for their constructive and insightful comments.

Conflicts of Interest: The authors declare no conflict of interest.

\section{Appendix A. Discretization of the Governing Equation}

In this section, the numerical procedure for solving Equation (17) is described. Figure A1 shows the schematic of connections in the numerical model.

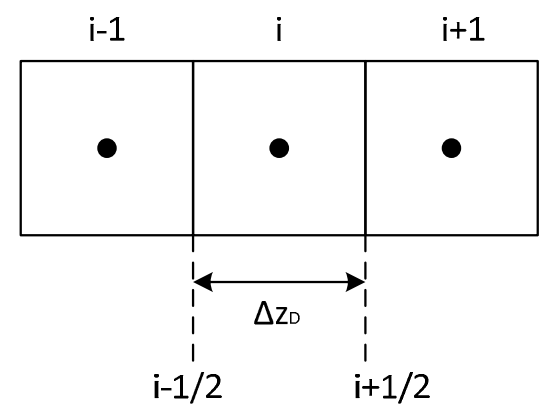

Figure A1. Schematic of connections in a finite difference discretization.

The discretized form of Equation (17) can be written as:

$$
\begin{aligned}
& N_{C a} \frac{1}{\Delta z_{D}} \frac{D(S)_{i+1 / 2}\left(S_{i+1}^{n+1}-S_{i}^{n+1}\right)-D(S)_{i-1 / 2}\left(S_{i}^{n+1}-S_{i-1}^{n+1}\right)}{\Delta z_{D}}-N_{G r} \frac{G(S)_{i+1 / 2}^{n+1}-G(S)_{i-1 / 2}^{n+1}}{\Delta z_{D}} \\
& -\frac{V(S)_{i+1 / 2}^{n+1}-V(S)_{i-1 / 2}^{n+1}}{\Delta z_{D}}=\frac{S_{i}^{n+1}-S_{i}^{n}}{\Delta t_{D}}
\end{aligned}
$$


where subscript $i=1,2,3, \ldots$ denotes the block index (position) and $\Delta z_{D}$ is the block size. Superscripts $n$ represent the time step index.

For the evaluation of coefficients at the grid-cell boundaries, two approaches have been used. Arithmetic mean is the formulation for evaluation of diffusion terms for $D(S)_{i+1 / 2}$ and $D(S)_{i-1 / 2}$.

$$
D(S)_{i+1 / 2}=\frac{1}{S_{i}-S_{i+1}} \int_{S_{i+1}}^{S_{i}} D(S) d S \text { and } D(S)_{i-1 / 2}=\frac{1}{S_{i-1}-S_{i}} \int_{S_{i}}^{S_{i-1}} D(S) d S
$$

whereas $V(S)$ and $G(S)$ on the interface blocks are approximated with their values on the upstream block. With these, Equation (A1) could be written as:

$$
\begin{aligned}
& {\left[N_{C a} \frac{\Delta t_{D} D(S)_{i-1 / 2}}{\Delta z_{D}^{2}}\right] S_{i-1}^{n+1}-\left[N_{C a} \frac{\Delta t_{D} D(S)_{i-1 / 2}}{\Delta z_{D}^{2}}+N_{C a} \frac{\Delta t_{D} D(S)_{i+1 / 2}}{\Delta z_{D}^{2}}+1\right] S_{i}^{n+1}} \\
& +\left[N_{C a} \frac{\Delta t_{D} D(S)_{i+1 / 2}}{\Delta z_{D}^{2}}\right] S_{i+1}^{n+1}=-S_{i}^{n}+\frac{N_{G r} \Delta t_{D}}{\Delta z_{D}}\left(G(S)_{i}^{n+1}-G(S)_{i-1}^{n+1}\right)+\frac{\Delta t_{D}}{\Delta z_{D}}\left(V(S)_{i}^{n+1}-V(S)_{i-1}^{n+1}\right)
\end{aligned}
$$

The numerical procedure that has been used here is depicted in Figure A2. As shown in this figure, Equation (A3) is written for all the grid blocks at every time step which results in a coupled set of algebraic equations in the following matrix form of $\mathbf{A x}=\mathbf{b}$.

$$
\begin{aligned}
& {\left[\begin{array}{cccccc}
-\left(d_{2}+d_{1}+1\right) & d_{2} & 0 & 0 & \ldots \ldots & 0 \\
d_{2} & -\left(d_{3}+d_{2}+1\right) & d_{3} & 0 & \ldots \ldots & 0 \\
0 & d_{3} & -\left(d_{4}+d_{3}+1\right) & d_{4} & \ldots \ldots & 0 \\
0 & 0 & d_{4} & -\left(d_{5}+d_{4}+1\right) & \ldots \ldots & 0 \\
\ldots \ldots & \ldots \ldots & \ldots \ldots & \ldots \ldots & \ldots \ldots \\
0 & 0 & 0 & 0 & d_{N} & -\left(d_{N}+1\right)
\end{array}\right]\left[\begin{array}{c}
S_{1} \\
S_{2} \\
S_{3} \\
S_{4} \\
S_{N}
\end{array}\right]^{n+1}} \\
& =\left[\begin{array}{c}
-S_{1}^{n}-\left(d_{1}\right)(1)+\beta N_{\cdot G r}\left(G(S)_{1}^{n+1}-0\right)+\beta\left(V(S)_{1}^{n+1}-1\right) \\
-S_{2}^{n}+\beta N_{G r}\left(G(S)_{2}^{n+1}-G(S)_{1}^{n+1}\right)+\beta\left(V(S)_{2}^{n+1}-V(S)_{1}^{n+1}\right) \\
-S_{3}^{n}+\beta N_{G r}\left(G(S)_{3}^{n+1}-G(S)_{2}^{n+1}\right)+\beta\left(V(S)_{3}^{n+1}-V(S)_{2}^{n+1}\right) \\
-S_{4}^{n}+\beta N_{G r}\left(G(S)_{4}^{n+1}-G(S)_{3}^{n+1}\right)+\beta\left(V(S)_{4}^{n+1}-V(S)_{3}^{n+1}\right) \\
-S_{N}^{n}+\beta N_{G r}\left(G(S)_{N}^{n+1}-G(S)_{N-1}^{n+1}\right)+\beta\left(V(S)_{N}^{n+1}-V(S)_{N-1}^{n+1}\right)
\end{array}\right]
\end{aligned}
$$

where $\alpha=\frac{\Delta t_{D}}{\left(\Delta z_{D}\right)^{2}}, \beta=\frac{\Delta t_{D}}{\Delta z_{D}}$ and $d_{i}=N_{C a} \alpha D_{i-1 / 2}, d_{i+1}=N_{C a} \alpha D_{i+1 / 2}$.

These sets of equations need to be solved simultaneously to determine the saturation distribution at each time and for every grid block. After initialization, all the coefficients of matrix A are evaluated at the new time level $\left(S^{n+1, v}\right)$ where $v$ is iteration step. Same as matrix $\mathrm{A}$, the coefficients of vector $\mathrm{b}$ are evaluated at the new time level, except the saturation at the current time level $\left(S_{i}^{n}\right)$. Now that all the coefficients are defined, saturation at the new time step $\left(S^{n+1, v+1}\right)$ can be evaluated iteratively until the convergence condition is achieved, which in this case is $\sqrt{\sum\left(S^{n+1, v+1}-S^{n+1, v}\right)^{2}} \leq 1 \times 10^{-10}$. 


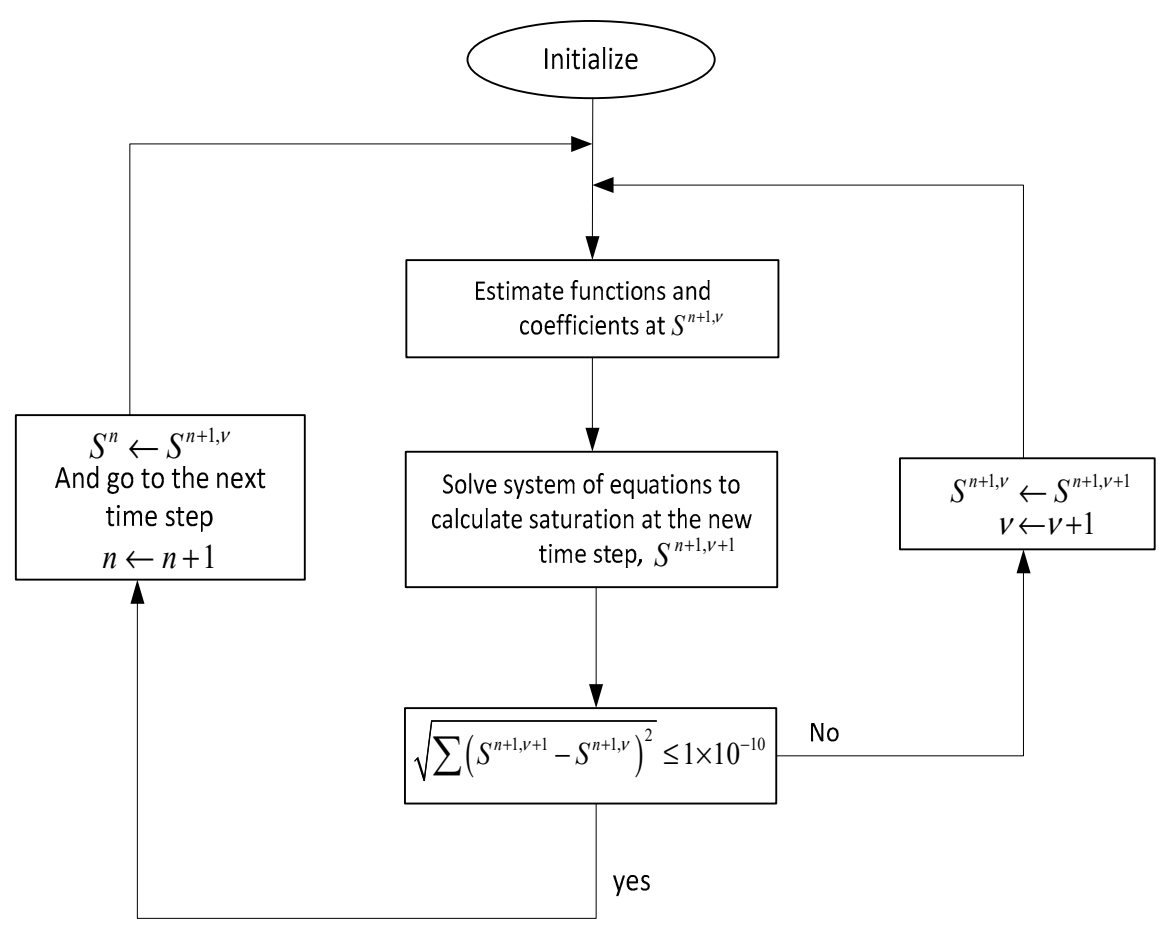

Figure A2. Numerical procedure algorithm for solution of Equation (A3).

\section{Appendix B. Numerical Model Validation}

The partial differential Equation (17) is solved using finite difference formulation. Discretization of one-dimensional equation is carried out by finite difference method in block-centered Cartesian domain with uniform grid blocks. A detailed description of the numerical procedure is presented in Appendix A.

To verify the accuracy of the developed numerical model, different analytical solutions that exist for simplified problems are compared with the numerical solution. Table A1 provides a list of the problems studied in this section.

Table A1. Problems studied for validation of numerical model.

\begin{tabular}{|c|c|c|c|c|}
\hline Problem & \multicolumn{2}{|c|}{ Coefficients in Equation (17) } & \multicolumn{2}{|l|}{ Final Equation } \\
\hline Capillary diffusion & $\begin{array}{l}D(S)=1 \\
V(S)=0\end{array}$ & $\begin{array}{l}N_{C a}=1 \\
N_{G r}=0\end{array}$ & $\frac{\partial S}{\partial t_{D}}=\frac{\partial^{2} S}{\partial z_{D}^{2}}$ & (A5) \\
\hline Advection-diffusion & \multirow{3}{*}{$\begin{array}{l}D(S)=1 \\
V(S)=S\end{array}$} & $\begin{array}{l}N_{C a}=1 \\
N_{G r}=0\end{array}$ & $\frac{\partial S}{\partial t_{D}}=\frac{\partial^{2} S}{\partial z_{D}^{2}}-\frac{\partial S}{\partial z_{D}}$ & (A6) \\
\hline $\begin{array}{l}\text { Advection-diffusion, Viscous } \\
\text { dominated flow } N_{C a}<<1\end{array}$ & & $\begin{array}{l}N_{C a}=0.02 \\
N_{G r}=0\end{array}$ & $\frac{\partial S}{\partial t_{D}}=0.02 \frac{\partial^{2} S}{\partial z_{D}^{2}}-\frac{\partial S}{\partial z_{D}}$ & (A7) \\
\hline Buckley-Leveret (Viscous Flow) & & $\begin{array}{l}N_{C a}=0 \\
N_{G r}=0\end{array}$ & $\frac{\partial S}{\partial t_{D}}=-\frac{\partial V(S)}{\partial z_{D}}$ & (A8) \\
\hline
\end{tabular}

For capillary diffusion equation (Equation (A5)), the analytical solution of saturation distribution as well as the average saturation are [48]:

$$
\begin{gathered}
S\left(z_{D}, t_{D}\right)=1-\frac{4}{\pi} \sum_{n=1}^{\infty} \frac{1}{(2 n-1)} \sin \left(\frac{(2 n-1) \pi}{2} z_{D}\right) \exp \left(-\left(\frac{(2 n-1) \pi}{2}\right)^{2} t_{D}\right) \\
\bar{S}\left(t_{D}\right)=1-\frac{8}{\pi^{2}} \sum_{n=1}^{\infty} \frac{1}{(2 n-1)^{2}} \exp \left(-\left(\frac{(2 n-1) \pi}{2}\right)^{2} t_{D}\right)
\end{gathered}
$$


Figure A3 compares the results obtained with the developed numerical simulation and the analytical solution obtained from Equations (A9) and (A10). This figure demonstrated that the numerical model has the ability to closely reproduce the analytical solution.

Next, the analytical solution of the advection-diffusion Equations (A6) and (A7) is compared with its numerical solution. The analytical solution for both equations and its average is as follows [49]:

$$
S\left(z_{D}, t_{D}\right)=1-4 \exp \left(\frac{1}{2 N_{C a}} z_{D}\right) \sum_{n=1}^{\infty} \frac{N_{C a} \lambda_{n} \sin \left(\sqrt{\lambda_{n}} z_{D}\right)}{2 \sqrt{\lambda_{n}}-\sin \left(2 \sqrt{\lambda_{n}}\right)} \frac{1}{\left(\frac{1}{4 N_{C a}}+N_{C a} \lambda_{n}\right)} \exp \left(-\left(\frac{1}{4 N_{C a}}+N_{C a} \lambda_{n}\right) t_{D}\right)
$$

where $\lambda_{n}$ s are the roots of: $\tan \left(\sqrt{\lambda_{n}}\right)+2 N_{C a} \sqrt{\lambda_{n}}=0$.

$$
\bar{S}\left(t_{D}\right)=1-4 \sum_{n=1}^{\infty} \frac{N_{C a} \lambda_{n}\left[\frac{1}{2 N_{C a}} \mathrm{e}^{\frac{1}{2 N_{C a}}} \sin \left(\sqrt{\lambda_{n}}\right)-\mathrm{e}^{\frac{1}{2 N_{C a}}} \sqrt{\lambda_{n}} \cos \left(\sqrt{\lambda_{n}}\right)+\sqrt{\lambda_{n}}\right]}{\left[2 \sqrt{\lambda_{n}}-\sin \left(2 \sqrt{\lambda_{n}}\right)\right]\left(\left(\frac{1}{2 N_{C a}}\right)^{2}+\lambda_{n}\right)\left(\frac{1}{4 N_{C a}}+N_{C a} \lambda_{n}\right)} \exp \left(-\left(\frac{1}{4 N_{C a}}+N_{C a} \lambda_{n}\right) t_{D}\right)
$$

Figures A4 and A5 compare the analytical and numerical solutions for advection-diffusion equation for $N_{C a}=1$ and $N_{C a}=0.02$, respectively.
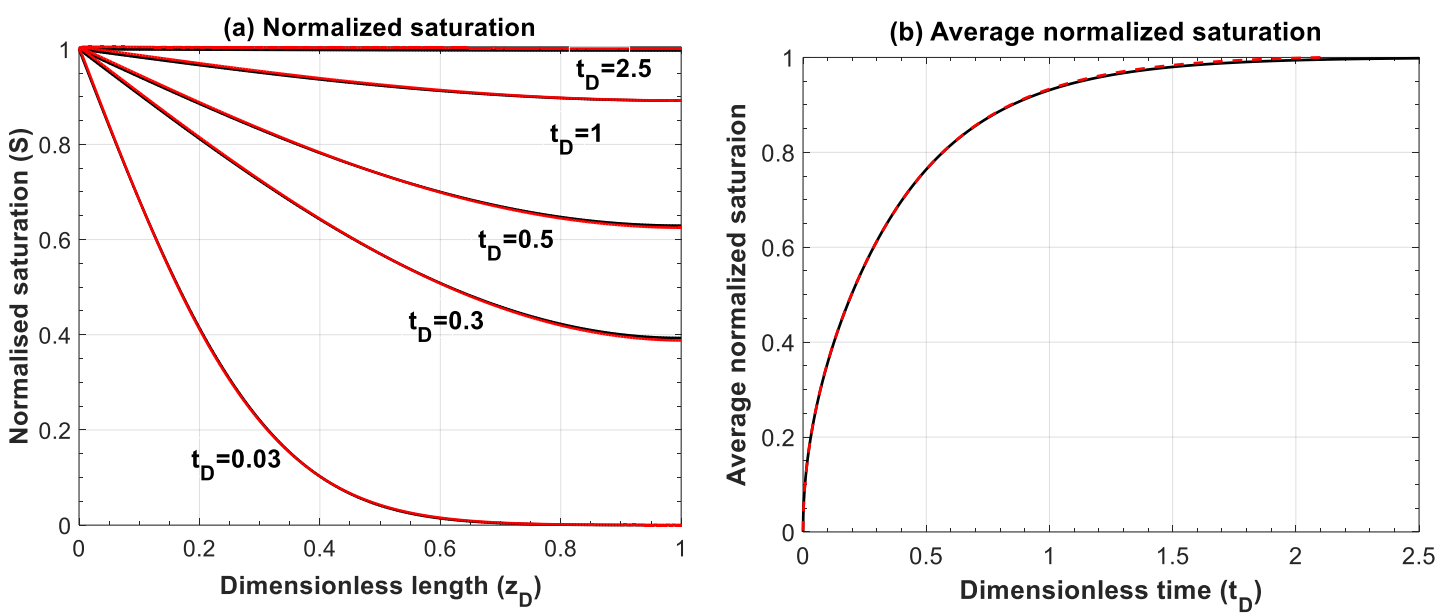

Figure A3. Comparison of (a) normalized saturation and (b) its average between numerical simulation (red lines) and analytical solution (black lines) for Equation (A5). Numerical simulations are performed for 200 grid blocks and with a time step of $1 \times 10^{-3}$.
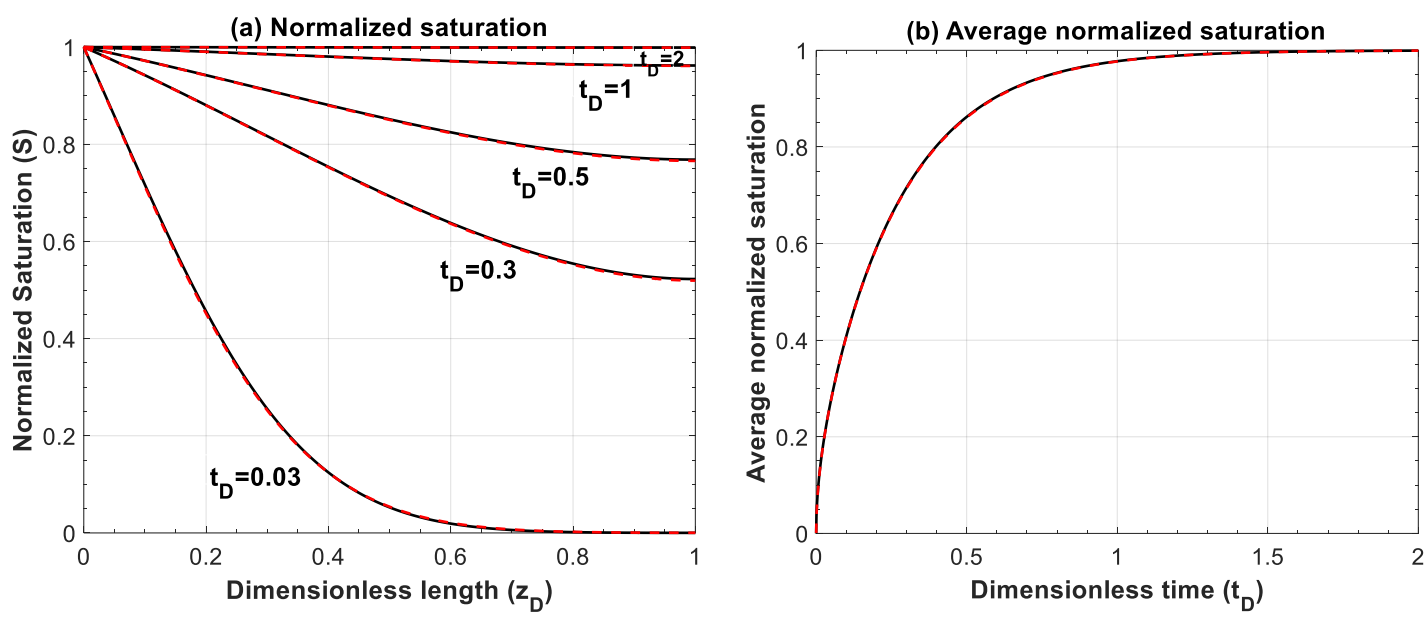

Figure A4. Comparison of (a) normalized saturation and (b) its average between numerical simulation (red lines) and analytical solution (black lines) for Equation (A6), $N_{C a}=1$. Numerical simulations are performed for 500 grid blocks and with a time step of $1 \times 10^{-3}$. 
Finally, the analytical solution of the well-known Buckley-Leveret model is compared with the numerical results here. The Buckley-Leveret problem describes immiscible displacement of one phase by another in the absence of capillary and gravity forces [50]. Setting $N_{C a}=N_{G r}=0$ results in Equation (A8), where viscous function, $V(S)$, has the form of fractional flow equation in Buckley-Leveret problem. For comparison between numerical and analytical solutions, $n c$ and $n b$ are set to 2. Figure A6 shows the comparison between analytical and numerical results for three different mobility ratios. Results show that the numerical model reproduces the front location fairly well at both low and large mobility ratios.
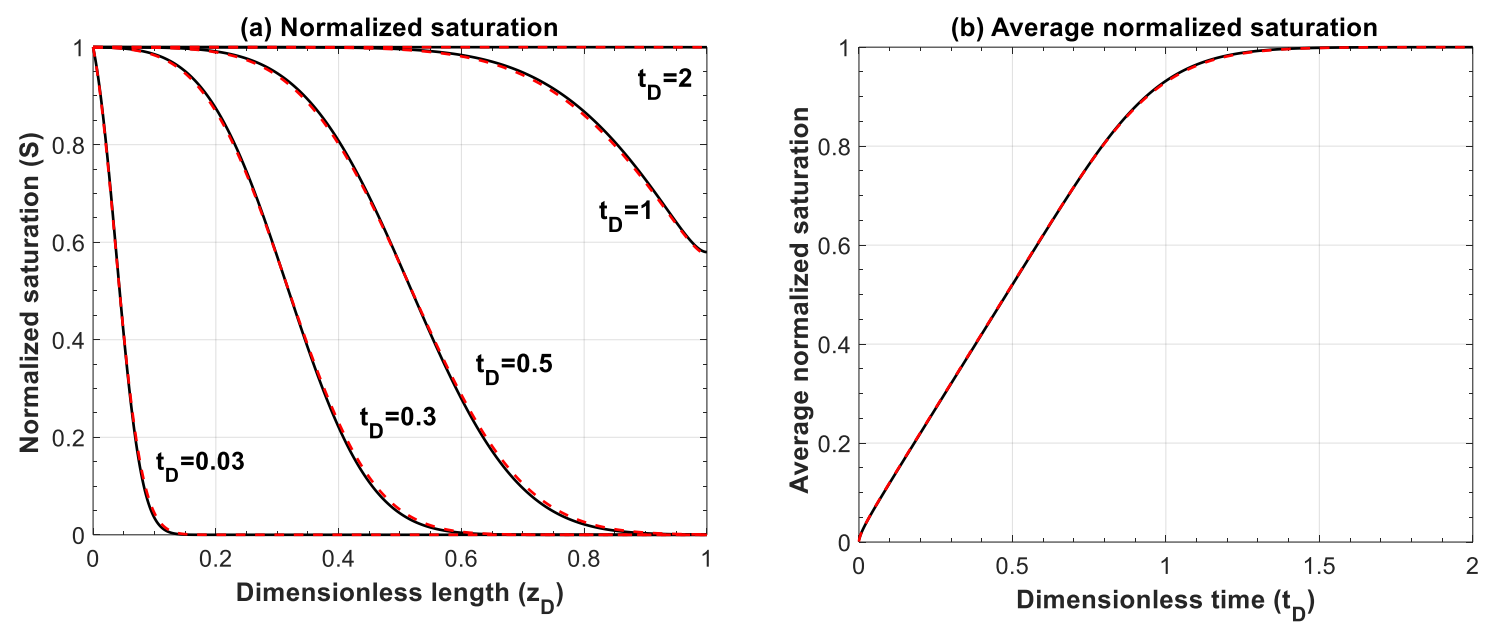

Figure A5. Comparison of (a) normalized saturation and (b) its average between numerical simulation (red lines) and analytical solution (black lines) for Equation (A7), $N_{C a}=0.02$. Numerical simulations are performed for 500 grid blocks and with a time step of $1 \times 10^{-3}$.

(a)

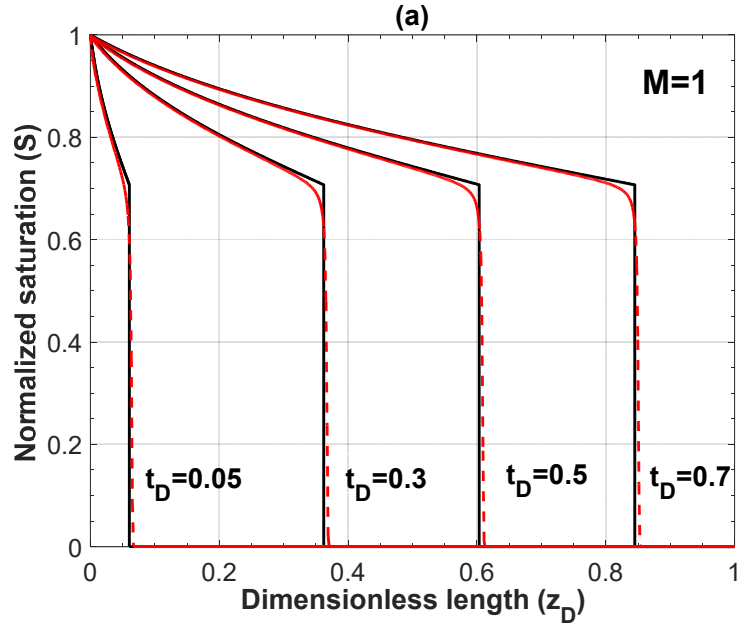

(b)

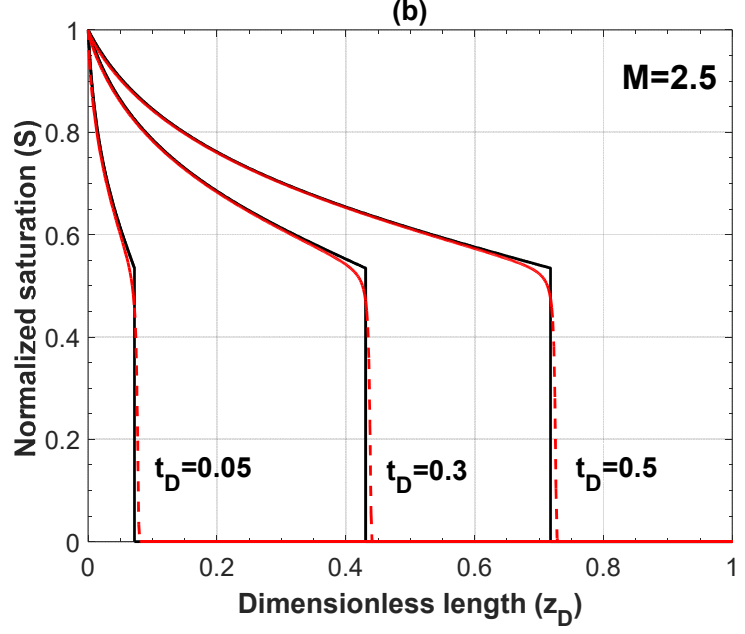

Figure A6. Cont. 
(c)

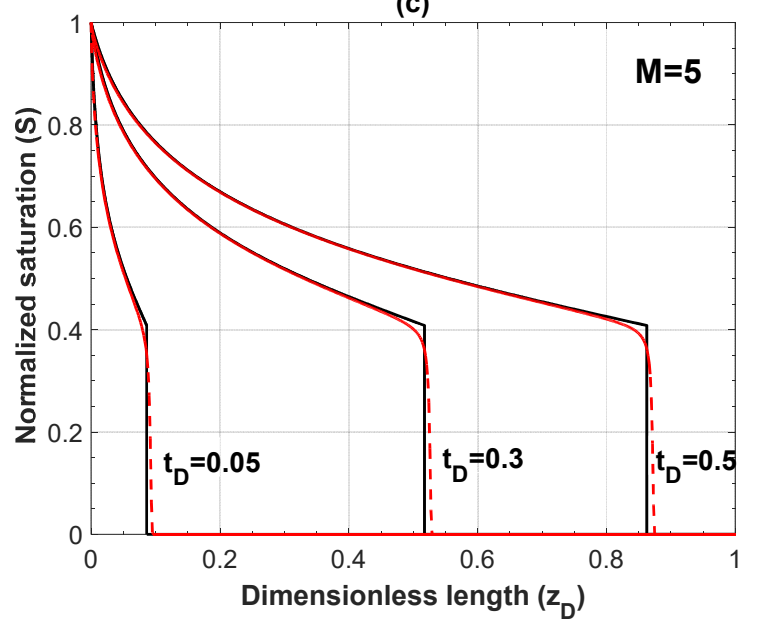

Figure A6. Comparison of analytical solution of Buckley-Leverett problem (black lines) and numerical results (red lines) for different mobility ratios of (a) $M=1$, (b) $M=2.5$, and (c) $M=5$ at different times. Number of grid blocks is 600 , dimensionless time step is $1 \times 10^{-4}$.

\section{References}

1. IPCC (Intergovernmental Panel on Climate Change). Special Report on Carbon Dioxide Capture and Storage; Metz, B., Davidson, O., De Coninck, H., Loos, M., Meyer, L., Eds.; Prepared by Working Group III of the Intergovernmental Panel on Climate Change; Cambridge University Press: Cambridge, UK; New York, NY, USA, 2005.

2. Le Quéré, C.; Moriarty, R.; Andrew, R.M.; Peters, G.P.; Ciais, P.; Friedlingstein, P.; Jones, S.D. Global carbon budget 2014. Earth Syst. Sci. Data 2015, 7, 47-85. [CrossRef]

3. Makhnenko, R.Y.; Vilarrasa, V.; Mylnikov, D.; Laloui, L. Hydromechanical aspects of $\mathrm{CO}_{2}$ breakthrough into clay-rich caprock. In Energy Procedia; Elsevier: Amsterdam, The Netherlands, 2017; Volume 114, pp. 3219-3228.

4. Emami-Meybodi, H.; Hassanzadeh, H.; Green, C.P.; Ennis-King, J. Convective dissolution of $\mathrm{CO}_{2}$ in saline aquifers: Progress in modeling and experiments. Int. J. Greenh. Gas Control 2015, 40, 238-266. [CrossRef]

5. Bear, J. Dynamics of Fluids in Porous Media; Elsevier: New York, NY, USA, 1972.

6. Nordbotten, J.M.; Celia, M.A.; Bachu, S. Injection and storage of $\mathrm{CO}_{2}$ in deep saline aquifers: Analytical solution for $\mathrm{CO}_{2}$ plume evolution during injection. Transp. Porous Media 2005, 58, 339-360. [CrossRef]

7. Dentz, M.; Tartakovsky, D.M. Abrupt-interface solution for carbon dioxide injection into porous media. Transp. Porous Media 2009, 79, 15-27. [CrossRef]

8. Vilarrasa, V.; Bolster, D.; Dentz, M.; Olivella, S.; Carrera, J. Effects of $\mathrm{CO}_{2}$ compressibility on $\mathrm{CO}_{2}$ storage in deep saline aquifers. Transp. Porous Media 2010, 85, 619-639. [CrossRef]

9. Houseworth, J.E. Matched boundary extrapolation solutions for $\mathrm{CO}_{2}$ well-injection into a saline aquifer. Transp. Porous Media 2012, 91, 813-831. [CrossRef]

10. Ide, S.T.; Jessen, K.; Orr, F.M. Storage of $\mathrm{CO}_{2}$ in saline aquifers: Effects of gravity, viscous, and capillary forces on amount and timing of trapping. Int. J. Greenh. Gas Control 2007, 1, 481-491. [CrossRef]

11. Kopp, A.; Class, H.; Helmig, R. Investigations on $\mathrm{CO}_{2}$ storage capacity in saline aquifers. Part 1. Dimensional analysis of flow processes and reservoir characteristics. Int. J. Greenh. Gas Control 2009, 3, 263-276. [CrossRef]

12. Kopp, A.; Class, H.; Helmig, R. Investigations on $\mathrm{CO}_{2}$ storage capacity in saline aquifers-Part 2: Estimation of storage capacity coefficients. Int. J. Greenh. Gas Control 2009, 3, 277-287. [CrossRef]

13. Bachu, S.; Celia, M.A. Assessing the potential for $\mathrm{CO}_{2}$ leakage, particularly through wells, from geological storage sites. Geophys. Monogr. Ser. 2009, 183, 203-216. [CrossRef]

14. Laurich, B.; Urai, J.L.; Desbois, G.; Vollmer, C.; Nussbaum, C. Microstructural evolution of an incipient fault zone in Opalinus Clay: Insights from an optical and electron microscopic study of ion-beam polished samples from the Main Fault in the Mt-Terri Underground Research Laboratory. J. Struct. Geol. 2014, 67, 107-128. [CrossRef] 
15. Zoback, M.D.; Gorelick, S.M. Earthquake triggering and large-scale geologic storage of carbon dioxide. Proc. Natl. Acad. Sci. USA 2012, 109, 10164-10168. [CrossRef] [PubMed]

16. Vilarrasa, V.; Carrera, J. Geologic carbon storage is unlikely to trigger large earthquakes and reactivate faults through which $\mathrm{CO}_{2}$ could leak. Proc. Natl. Acad. Sci. USA 2015, 112, 5938-5943. [CrossRef] [PubMed]

17. Haekes, C.D.; McLellan, P.J.; Bachu, S. Geomechanical factors affecting geological storage of $\mathrm{CO}_{2}$ in depleted oil and gas reservoirs. J. Can. Pet. Technol. 2005, 44, 52-61. [CrossRef]

18. Rutqvist, J. The Geomechanics of $\mathrm{CO}_{2}$ storage in deep sedimentary formations. Geotech. Geol. Eng. 2012, 30, 525-551. [CrossRef]

19. Celia, M.A.; Nordbotten, J.M.; Bachu, S.; Dobossy, M.; Court, B. Risk of leakage versus depth of injection in geological storage. Energy Procedia 2009, 1, 2573-2580. [CrossRef]

20. Nordbotten, J.M.; Celia, M.A.; Bachu, S.; Dahle, H.K. Semianalytical solution for $\mathrm{CO}_{2}$ leakage through an abandoned well. Environ. Sci. Technol. 2005, 39, 602-611. [CrossRef] [PubMed]

21. Nordbotten, J.M.; Celia, M.A.; Bachu, S. Analytical solutions for leakage rates through abandoned wells. Water Resour. Res. 2004, 40. [CrossRef]

22. Nordbotten, J.M.; Kavetski, D.; Celia, M.A.; Bachu, S. Model for $\mathrm{CO}_{2}$ leakage including multiple geological layers and multiple leaky wells. Environ. Sci. Technol. 2009, 43, 743-749. [CrossRef] [PubMed]

23. Dejam, M.; Hassanzadeh, H. Diffusive leakage of brine from aquifers during $\mathrm{CO}_{2}$ geological storage. Adv. Water Resour. 2018, 111, 36-57. [CrossRef]

24. Dejam, M.; Hassanzadeh, H. The role of natural fractures of finite double-porosity aquifers on diffusive leakage of brine during geological storage of $\mathrm{CO}_{2}$. Int. J. Greenh. Gas Control 2018, 78, 177-197. [CrossRef]

25. Pruess, K. Leakage of $\mathrm{CO}_{2}$ from geologic storage: Role of secondary accumulation at shallow depth. Int. J. Greenh. Gas Control 2008, 2, 37-46. [CrossRef]

26. Rinaldi, A.P.; Jeanne, P.; Rutqvist, J.; Cappa, F.; Guglielmi, Y. Effects of fault-zone architecture on earthquake magnitude and gas leakage related to $\mathrm{CO}_{2}$ injection in a multi-layered sedimentary system. Greenh. Gases Sci. Technol. 2014, 4, 99-120. [CrossRef]

27. Rinaldi, A.P.; Vilarrasa, V.; Rutqvist, J.; Cappa, F. Fault reactivation during $\mathrm{CO}_{2}$ sequestration: Effects of well orientation on seismicity and leakage. Greenh. Gases Sci. Technol. 2015, 5, 645-656. [CrossRef]

28. Rutqvist, J.; Rinaldi, A.P.; Cappa, F.; Jeanne, P.; Mazzoldi, A.; Urpi, L.; Guglielmi, Y.; Vilarrasa, V. Fault activation and induced seismicity in geologic carbon storage-Lessons learned from recent modeling studies. J. Rock Mech. Geotech. Eng. 2016, 8, 789-804. [CrossRef]

29. Kang, M.; Nordbotten, J.M.; Doster, F.; Celia, M.A. Analytical solutions for two-phase subsurface flow to a leaky fault considering vertical flow effects and fault properties. Water Resour. Res. 2014, 50, 3536-3552. [CrossRef]

30. Brooks, R.; Corey, A. Hydraulic Properties of Porous Media; Hydro Paper; Colorado State University: Fort Collins, CO, USA, 1964.

31. Firoozabadi, A.; Ishimoto, K. Reinfiltration in fractured porous media: Part 1 -One dimensional model. SPE Adv. Technol. Ser. 1994, 2, 35-42. [CrossRef]

32. Rosado-Vazquez, F.J.; Rangel-German, E.R.; Rodriguez-De La Garza, F. Analytical model for vertical oil/water displacement under combined viscous, capillary, and gravity effects. In SPE Western Regional/AAPG Pacific Section/GSA Cordilleran Section Joint Meeting; Society of Petroleum Engineers: Anchorage, AK, USA, 2006.

33. Bachu, S.; Bennion, B. Effects of in-situ conditions on relative permeability characteristics of $\mathrm{CO}_{2}$-brine systems. Environ. Geol. 2008, 54, 1707-1722. [CrossRef]

34. Environment and Climate Change Canada. Canadian Environmental Sustainability Indicators: Greenhouse Gas Emissions. 2017. Available online: http:/ / www.ec.gc.ca/indicateurs-indicators/18F3BB9C-43A1-491E9835-76C8DB9DDFA3/GHGEmissions_EN.pdf (accessed on 1 April 2017).

35. Bachu, S. Screening and ranking of sedimentary basins for sequestration of $\mathrm{CO}_{2}$ in geological media in response to climate change. Environ. Geol. 2003, 44, 277-289. [CrossRef]

36. Michael, K.; Bachu, S.; Buschkuehle, B.E.; Haug, K.; Talman, S. Comprehensive characterization of a potential site for $\mathrm{CO}_{2}$ geological storage in central Alberta, Canada. In Carbon Dioxide Sequestration in Geological Media-State of the Science: AAPG Studies in Geology; The American Association of Petroleum Geologists: Tulsa, OK, USA, 2009; pp. 227-240. [CrossRef] 
37. Bennion, B.; Bachu, S. Relative permeability characteristics for supercritical $\mathrm{CO}_{2}$ displacing water in a variety of potential sequestration zones in the Western Canada sedimentary basin. In SPE Annual Technical Conference and Exhibition; Society of Petroleum Engineers: Dallas, TX, USA, 2005.

38. Bennion, B.; Bachu, S. The impact of interfacial tension and pore-size distribution/capillary pressure character on $\mathrm{CO}_{2}$ relative permeability at reservoir conditions in $\mathrm{CO}_{2}$-brine systems. In SPE/DOE Symposium on Improved Oil Recovery; Society of Petroleum Engineers: Tulsa, OK, USA, 2006.

39. Bennion, D.B.; Bachu, S. Dependence on temperature, pressure, and salinity of the IFT and relative permeability displacement characteristics of $\mathrm{CO}_{2}$ injected in deep saline aquifers. In SPE Annual Technical Conference and Exhibition; Society of Petroleum Engineers: San Antonio, TX, USA, 2006.

40. Bennion, B.; Bachu, S. Drainage and imbibition relative permeability relationships for supercritical $\mathrm{CO}_{2} / \mathrm{Brine}$ and $\mathrm{H}_{2} \mathrm{~S}$ /Brine systems in intergranular sandstone, carbonate, shale, and anhydrite rocks. SPE Reserv. Eval. Eng. 2008, 11, 487-496. [CrossRef]

41. Bennion, D.B.; Bachu, S. Drainage and imbibition $\mathrm{CO}_{2}$ /brine relative permeability curves at reservoir conditions for carbonate formations. In SPE Annual Technical Conference and Exhibition; Society of Petroleum Engineers: Florence, Italy, 2010.

42. Bachu, $\mathrm{S}$. Drainage and imbibition $\mathrm{CO}_{2}$ / brine relative permeability curves at in situ conditions for sandstone formations in Western Canada. Energy Procedia 2013, 37, 4428-4436. [CrossRef]

43. Rowe, A.M.; Chou, J.C.S. Pressure-volume-temperature-concentration relation of aqueous sodium chloride solutions. J. Chem. Eng. Data 1970, 15, 61-66. [CrossRef]

44. Hassanzadeh, H.; Pooladi-Darvish, M.; Elsharkawy, A.M.; Keith, D.W.; Leonenko, Y. Predicting PVT data for $\mathrm{CO}_{2}$-brine mixtures for black-oil simulation of $\mathrm{CO}_{2}$ geological storage. Int. J. Greenh. Gas Control 2008, 2, 65-77. [CrossRef]

45. Berg, S.; Ott, H. Stability of $\mathrm{CO}_{2}$-brine immiscible displacement. Int. J. Greenh. Gas Control 2012, 11, $188-203$. [CrossRef]

46. Polak, S.; Cinar, Y.; Holt, T.; Torsæter, O. Use of low- and high-IFT fluid systems in experimental and numerical modelling of systems that mimic $\mathrm{CO}_{2}$ storage in deep saline formations. J. Pet. Sci. Eng. 2015, 129, 97-109. [CrossRef]

47. Celia, M.A.; Nordbotten, J.M.; Court, B.; Dobossy, M.; Bachu, S. Field-scale application of a semi-analytical model for estimation of $\mathrm{CO}_{2}$ and brine leakage along old wells. Int. J. Greenh. Gas Control 2011, 5, 257-269. [CrossRef]

48. Hassanzadeh, H.M.; Pooladi-Darvish, M.; Keith, D.W. Modelling of convective mixing in $\mathrm{CO}_{2}$ storage. J. Can. Pet. Technol. 2005, 44, 43-51. [CrossRef]

49. Ozisik, M.N. Heat Conduction; John Wiley \& Sons: New York, NY, USA, 1993; ISBN 0471532568.

50. Buckley, S.E.; Leverett, M.C. Mechanism of Fluid Displacement in Sands. Trans. AIME 1942, 146, $107-116$. [CrossRef]

(C) 2018 by the authors. Licensee MDPI, Basel, Switzerland. This article is an open access article distributed under the terms and conditions of the Creative Commons Attribution (CC BY) license (http:/ / creativecommons.org/licenses/by/4.0/). 